\title{
Drosophila as a genetic and cellular model for studies on axonal growth
}

\author{
Natalia Sánchez-Soriano ${ }^{1}$, Guy Tear ${ }^{2}$, Paul Whitington ${ }^{3}$ and \\ Andreas Prokop*1
}

Address: ${ }^{1}$ The Wellcome Trust Centre for Cell-Matrix Research, Faculty of Life Sciences, The University of Manchester, Manchester, UK, ${ }^{2} \mathrm{MRC}$ Centre for Developmental Neurobiology, Guy's Campus, King's College, London, UK and ${ }^{3}$ Department of Anatomy and Cell Biology, University of Melbourne, Victoria, Australia

Email: Natalia Sánchez-Soriano - Nsanchez@manchester.ac.uk; Guy Tear - Guy.Tear@kcl.ac.uk;

Paul Whitington - P.Whitington@unimelb.edu.au; Andreas Prokop* - Andreas.Prokop@manchester.ac.uk

* Corresponding author

Published: 2 May 2007

Neural Development 2007, 2:9 doi:10.1186/1749-8104-2-9
Received: 28 January 2007

Accepted: 2 May 2007

This article is available from: http://www.neuraldevelopment.com/content/2/I/9

(C) 2007 Sánchez-Soriano et al; licensee BioMed Central Ltd.

This is an open access article distributed under the terms of the Creative Commons Attribution License (http://creativecommons.org/licenses/by/2.0), which permits unrestricted use, distribution, and reproduction in any medium, provided the original work is properly cited.

\begin{abstract}
One of the most fascinating processes during nervous system development is the establishment of stereotypic neuronal networks. An essential step in this process is the outgrowth and precise navigation (pathfinding) of axons and dendrites towards their synaptic partner cells. This phenomenon was first described more than a century ago and, over the past decades, increasing insights have been gained into the cellular and molecular mechanisms regulating neuronal growth and navigation. Progress in this area has been greatly assisted by the use of simple and genetically tractable invertebrate model systems, such as the fruit fly Drosophila melanogaster. This review is dedicated to Drosophila as a genetic and cellular model to study axonal growth and demonstrates how it can and has been used for this research. We describe the various cellular systems of Drosophila used for such studies, insights into axonal growth cones and their cytoskeletal dynamics, and summarise identified molecular signalling pathways required for growth cone navigation, with particular focus on pathfinding decisions in the ventral nerve cord of Drosophila embryos. These Drosophila-specific aspects are viewed in the general context of our current knowledge about neuronal growth.
\end{abstract}

\section{Background}

The function of a nervous system depends on the proper arrangement of its cellular elements, that is, neurons and glia cells. Amongst these, neurons bear axonal processes that establish synaptic contacts with other cells (neurons, muscles or gland cells) that can be a significant distance away. The transfer of information between these cells is the key feature of nervous system function and is usually mediated by action potentials that propagate along axons and are passed on to other cells at synapses. The wiring of such a system has to be precise and reproducible from individual to individual, as was first highlighted by Ramón y Cajal for the nervous systems of humans, other vertebrates, and also invertebrates [1]. Such precision is achieved during development through the guided growth of axons along specific paths, a process clearly governed by genetic mechanisms $[2,3]$.

Essential work contributing to our current understanding of axonal growth has been carried out in vertebrates and 
invertebrates alike, in many instances demonstrating the conservation of principal mechanisms across the animal kingdom. One strategy towards improving molecular insights into axonal growth is the use of genetically tractable invertebrate model organisms, such as the worm Caenorhabditis elegans or the fruit fly Drosophila melanogaster. The strength of these species lies in their amenability to genetic manipulation (see below) and the fact that their nervous systems are composed of relatively low numbers of cellular elements. Whereas specific neuronal connections in vertebrates are usually formed by larger groups of neurons that develop and act in parallel, these connections are mostly represented by unique, individually recognisable neurons in invertebrates. Studies capitalising on such identifiable neurons, for example in insects, have helped to unravel principles of neuronal circuit formation. For example, the initial observation of guidepost cells as stepping stones for axonal growth came from studies of the grasshopper limb bud [4]. The concept of pioneer guidance, which proposes that axonal tracts are established by single pioneer neurons that are subsequently used as guidance cues for follower neurons, was discovered in vertebrates [5]. However, work on insects has helped to refine these concepts ('selective fasciculation' and 'labelled pathways' hypotheses) [6-8] and to contribute molecular players [9].

Once it was revealed that Drosophila embryos were experimentally accessible and largely homologous to grasshoppers at the single cell level [10], insights that had to that date mostly been gained on larger insects could be transferred into a genetically tractable model system. Such work in Drosophila was further fuelled by the development of new technologies, strategies and molecular tools, such as specific anatomical antibody probes $[11,12]$ and the development of ever more sophisticated genetic screening strategies [13]. Furthermore, such research has profited enormously from the increasingly well organised research environment of Drosophila, including the systematic generation and provision at a large scale of new genetic tools and mutant fly stocks, and the improvement of access to research-relevant information [14-18].

Undoubtedly, the use of Drosophila as a model system for the study of axonal growth has been a prolific endeavour, providing a plethora of novel and/or refined insights into relevant molecular mechanisms, many of which have been shown to be conserved in higher organisms. This review will provide an overview of the major cellular model systems established for the fly, our current insights into Drosophila growth cones (the key structure executing axonal growth), the housekeeping machinery regulating the cytoskeletal dynamics required for axonal growth, and the signalling events involved in axon guidance, focussing on cellular models in the Drosophila embryo.

\section{Models for axonal growth in Drosophila}

One of the major strengths of Drosophila lies in its use as a model where axonal growth can be studied in situ. A widely used strategy for the unbiased discovery of neuronal growth mechanisms in Drosophila is the search for mutations that cause morphological aberrations of axonal tracts or neuronal connections in situ. Subsequently, the genes associated with such mutations can be identified, and the molecular nature, function and type of interactions of their products can be studied. To facilitate such genetic screens and functional studies of gene action, descriptions of axonal pathways and neuronal connections in wild-type animals have been provided for a number of different neural systems in Drosophila. A selection of these cellular models is illustrated in Figure 1, and some of their principal features will be discussed below.

First, neurons of all classes, that is, sensory neurons, interneurons and motorneurons, have been used for studies of axonal growth in Drosophila (red, green and blue in Figure 1, respectively). The principal structures of vertebrate and invertebrate neurons have been proposed to be homologous [19], despite there being certain organisational differences (Figure 2). These differences may be associated with deviations in some aspects of axonal pathfinding behaviours (details in Figure 2). For example, in the vertebrate trunk, sensory neurons are (pseudo-)unipolar and located in the dorsal root ganglia derived from a migratory stream of neural crest cells [20]. In contrast, cell bodies of sensory neurons in Drosophila are usually bi- or multipolar and are born and located in the periphery close to the sense organs they innervate or represent. Therefore, sensory axons in Drosophila grow unidirectionally towards the central nervous system (CNS), whereas sensory neurites in vertebrates bifurcate and grow bidirectionally both towards the CNS and into the periphery. A clear exception to this rule are the ocellar photoreceptors of Drosophila (located on the dorsal surface of the head; Figure $1 \mathrm{c}, \mathrm{d}$ ), which do not form axons themselves, but are connected to the brain via interneurons [21]. Somata of inter- and motorneurons are commonly multipolar in vertebrates and located in the synaptic region (grey matter; Figure 2b). In contrast, cell bodies of comparable neurons in Drosophila are unipolar and localised outside the neuropile within the cortex of the neuromeres. Finally, in vertebrates, axons ascending and descending to/from the brain are located in defined tracts in the white matter (1-3 in Figure 2b) where they become heavily myelinated, whereas comparable axons in Drosophila are located in the synaptic neuropile and usually lack glial ensheathment. Hence, mechanisms placing ascending/descending axons in the Drosophila neuropile might be distinct from those placing them in the white matter in vertebrates. Alternatively, if the same guidance cues are utilised, their spatial 


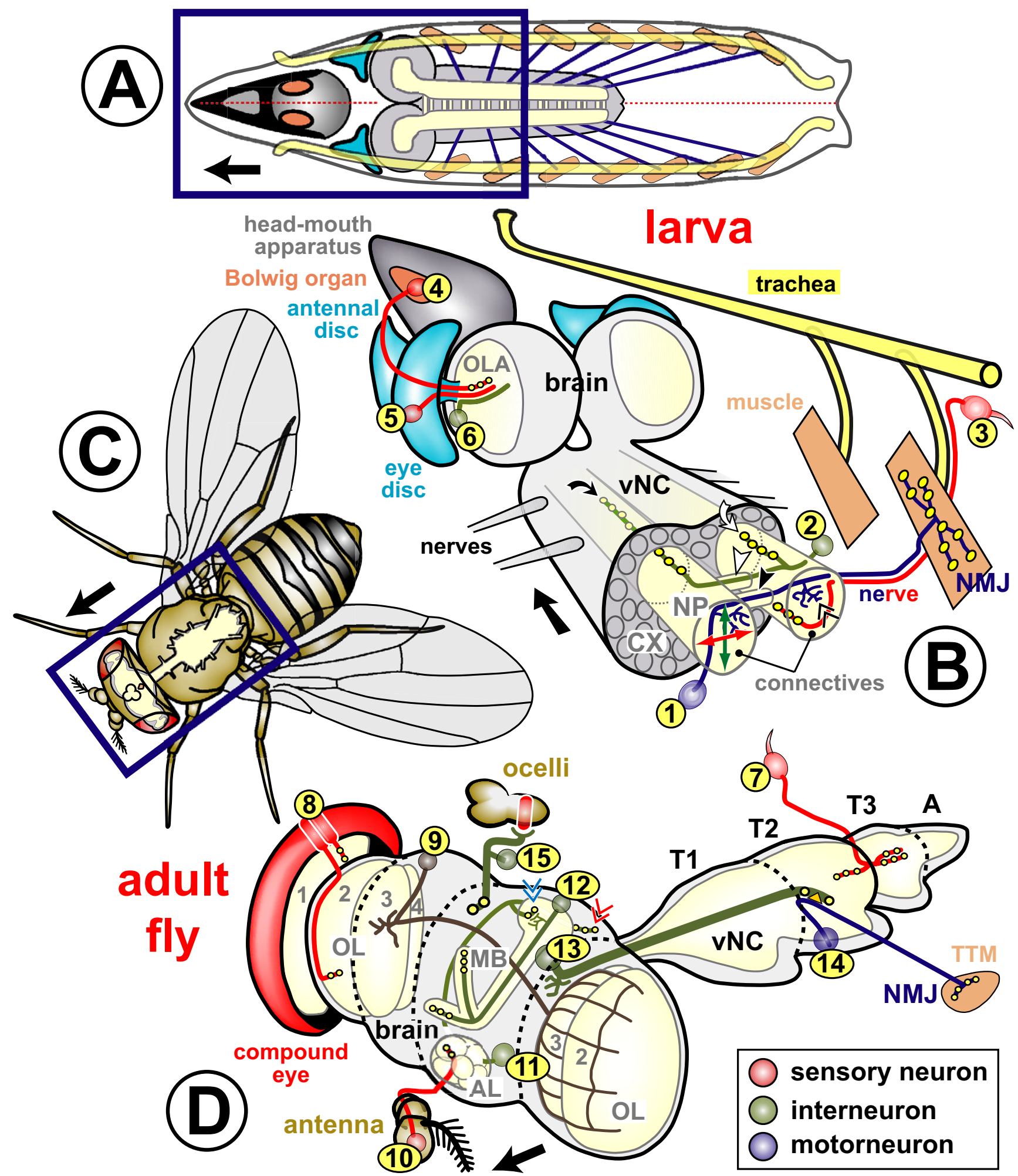

Figure I 


\section{Figure I}

Neurons used for studies on neuronal growth at different stages of Drosophila development. (a,c) Horizontal views of a Drosophila larva and adult fly, respectively, illustrating the position of the CNS (grey and cream) in relation to other body structures. (b,d) Three-dimensional extracts from the areas boxed in dark blue in $(a, c)$, respectively. The cell body area of the CNS (cortex $(\mathrm{CX})$ ) is shown in light grey, and the neuritic/synaptic area (neuropile (NP)) in cream (only relevant neuropile structures are shown in $(b, d)$ ). Black arrows point anterior, morphological structures are annotated in colour code, and neuronal classes are explained in the box at bottom right. The various model neurons are marked with numbers in yellow circles, explained below. Many neurons of the larval trunk can be studied from their birth in the embryo through to the mature synaptic stage. Amongst these, motorneurons (I) project towards the dorsal zone of ipsilateral or ipsi- and contralateral connectives (where they form dendrites; double chevron), from where they enter specific branches of peripheral nerves leading towards their target muscles, on which they form neuromuscular junctions (NMJ; yellow circles represent chemical synapses). Projections of larval interneurons (2) are restricted to the neuropile. Sensory neurons of the trunk (3) project along tracheal branches and motoraxons towards the ventral nerve cord ( $\mathrm{vNC}$ ) where they innervate the ventral domain of connectives $[192,195,196,198-200,236]$. Sensory neurons in the embryonic trunk have been used, for example, to study the actin-microtubule linker molecule Short stop, signalling through Robo or Notch receptors, or the spatial arrangement of axons in the neuropile [197,202,203,255]. Projections of neurons I, 2 and 3 in the neuropile of the ventral nerve cord can be classified with respect to their anteroposterior extension within the segment (white curved arrow) or across segments (black curved arrow), their dorsoventral and mediolateral position in connectives (green and red double arrows, respectively), their ipsilateral (neuron 3) versus contralateral (neurons I and 2) nature, and their projection through anterior (white arrowhead) versus posterior commissure (black arrowhead; see details in 'Signalling mechanisms involved in axonal pathfinding in Drosophila' above). In the embryonic/larval head region (4), the Bolwig organ has been used for studies of neuronal growth. It contains somata of I 2 photoreceptor cells [306], the axons of which form the Bolwig nerve projecting over the antennal and eye discs via the optic stalk into the optic lobe anlage (OLA) [26,307]. The Bolwig nerve is joined by successively outgrowing waves of axons of photoreceptor neurons (5), which are specified in the eye disc during larval and pupal stages. The optic lobe pioneer neuron (6), a projection neuron of embryonic origin, seems to be used as a guide within the OLA by the Bolwig nerve and photoreceptor axons [308,309]. Sensory neurons of the adult trunk (7) develop de novo during larval and pupal stages (with a few exceptions) [3 I0] and terminate in the vNC neuropile (TI-3 and A indicate the three thoracic and fused abdominal segments). They can be analysed from the time of birth through to the fully differentiated stage [3II,3I2], and have been used to study features, such as segment-specific growth regulation (homeotic genes), or the influence of adhesive interactions (Dscam), axonal transport (cut up, the dynein light chain) or of size alterations (gigas) on neuronal growth behaviour [3। I,3 I3-3। 5]. Photoreceptor cells in the adult compound eye (8) form a precise retinotopic map in the optic lobe (OL: grey I, lamina; 2, medulla; 3 , lobula; 4, lobula plate) established during larval (see neuron 5) and pupal stages, and the genetic mechanisms regulating these precise growth decisions are beginning to be unravelled [3/6-3 |8]. Interneurons postsynaptic to photoreceptor neurons are well described [317,319] but seem not to have been used for studies of growth mechanisms so far, with the exception of a group of 20-30 dorsal cluster neurons (9; targeted by atoGal4-I4A), which form dendrites in the ipsilateral optic lobe and project through the dorsal commissure to innervate the contralateral lobula and medulla [320-322]. Olfactory neurons in the third antennal segment $(10)$ and the maxillary palp (not shown) project from the antenna into the antennal lobe (AL) where they terminate in specific glomeruli in a reproducible pattern correlating with the class of odorant receptor they express; the genetic regulation of this growth behaviour is under investigation [39]. The major output from the AL is constituted by projection neurons (II), which are postsynaptic to olfactory neurons and innervate the lateral horn (red double chevron) and the calyx (blue double chevron), a dorsal structure of the mushroom bodies (MB) [39]. The mushroom bodies are the brain structures responsible for olfactory learning in Drosophila [323,324], and its intrinsic interneurons (Kenyon cells (I2)) project through the calyx and pedunculus where many of them bifurcate to project into the vertical $\alpha / \alpha^{\prime}$-and the horizontal $\beta / \beta^{\prime} / \gamma-$ lobes, simultaneously [325]. The large giant fibre neuron (13) connects the optic system via a large diameter axon with motorneurons in the second thoracic segment (14), innervating the tergotrochanteral muscle (TTM; responsible for the visually induced jump escape response) via chemical and electrical (orange triangle) synapses [326]. Giant fibre axons grow out during late larval/pupal stages and have been used to study growth regulatory mechanism, such as the influence of Rho-like GTPases or the role of the E2 ubiquitin ligase Bendless [326]. Ocellar photoreceptor neurons do not send out their own axons but are connected to the brain via large interneurons, the cell bodies of which are located in the brain originally, but migrate into the periphery during pupal development (I5). The pathfinding of these interneurons depends on a set of short-lived pioneer neurons that, in turn, require the extracellular matrix molecule laminin, the transmembrane receptor neurotactin and its ligand Amalgam for proper outgrowth [2I,239,24I]. Further potentially attractive models for studies of neuronal growth that are not shown here are auditory sensory neurons [327], and axonal fascicles in the ventral nerve cord of late Drosophila larvae representing paused interneurons of the future adult CNS (not shown) [209]. 

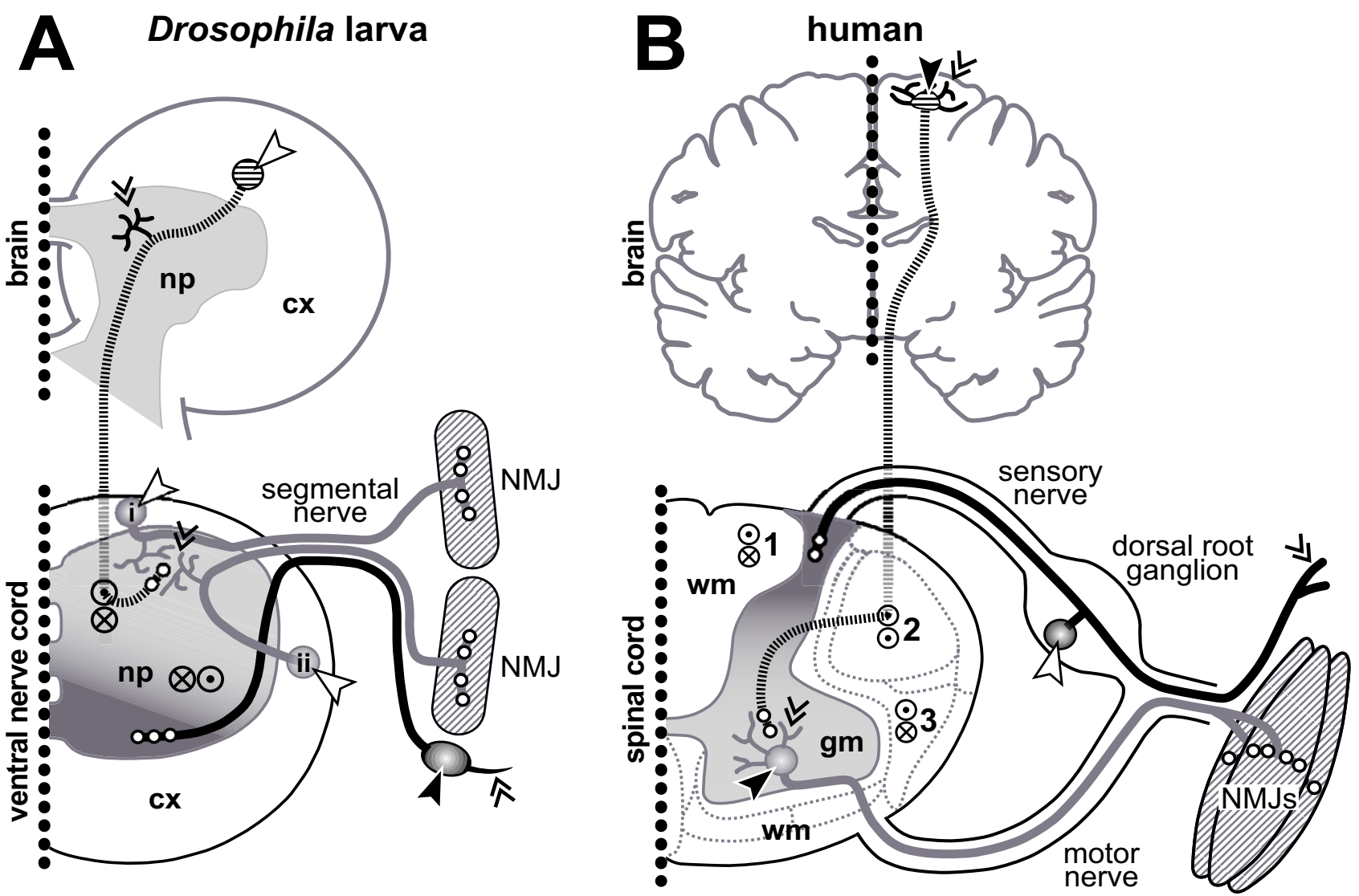

\begin{tabular}{|llclll|}
\hline$\theta$ & descending neuron & oo & output synapses & $\bullet \bullet$ & midline \\
0 & motorneuron & muscle fibres & np & neuropile \\
0 & sensory neuron & & synaptic area & cx & cortex \\
4 & mono-/unipolar soma & - & axon tracts in wm & gm & grey matter \\
$\Delta$ & bi-/multipolar soma & $\odot$ & descending axon & wm & white matter \\
$\wedge$ & dendrite & $\otimes$ & ascending axon & & \\
\hline
\end{tabular}

Figure 2

Comparing principal features of neuronal organisation and growth in Drosophila (larva) and vertebrates (human). (a) Saggital section (one body half; dotted line is midline) through the larval brain and ventral nerve cord (compare Figure la,b). (b) Saggital section through the adult human brain and one half of the spinal cord. Symbols are explained in the box below. Whereas axons of unipolar inter- and motorneurons in Drosophila have to grow into the synaptic area where they form dendrites, comparable neurons in vertebrates are multipolar and locate themselves in the synaptic area. All Drosophila motorneurons locate their dendrites in the dorsal neuropile, regardless of their soma position (see 'i' versus 'ii') [236]. Vice versa, sensory somata in Drosophila are located next to their dendrites, whereas cell bodies of most sensory neurons in vertebrates are grouped together in the dorsal root ganglia. Sensory output (dark grey) and motor input areas (bright grey) are inverted in both phyla, which might be explained through a general dorsoventral body axis inversion between vertebrates and arthropods [328], that is, not represent an organisational difference between their CNS. Ascending/descending axons in Drosophila are non-myelinated and project through the synaptic area (compare neurons 2 and I 3 in Figure I) where they take on characteristic positions [236,329]. In vertebrates, ascending/descending axons are myelinated and positioned outside the synaptic area, grouping into characteristic tracts in defined positions of the white matter; examples named here: fasciculus cuneatus (I), tractus corticospinalis lateralis (2; pyramidal tract; only descending), and tractus spinothalamicus lateralis (3). 
expression must differ considerably between vertebrates and arthropods.

Second, Drosophila is a holometabolous insect that exists as a maggot during larval life but is substantially reorganised into the adult fly during metamorphosis at the intermediate pupal stage. This process is not dissimilar to metamorphic events known from lower vertebrates, such as amphibians. One phase of de novo axonal growth takes place in the embryo, and a vast number of these cellular elements are maintained into the adult stage, albeit being remodelled during the pupal period [22]. However, to adapt to the far more complex behavioural repertoires of the adult, a second phase of de novo neurogenesis and axonal growth is initiated during larval life and completed during the process of metamorphosis. There is abundant evidence that common cellular and molecular mechanisms for axon guidance apply at both stages, allowing us, in many instances, to study the same molecules with the multiple techniques and cellular systems available for both stages of axonal growth in Drosophila [3].

Cellular models from both developmental phases (Figure $1 \mathrm{a}$, $\mathrm{b}$ versus $1 \mathrm{c}, \mathrm{d}$ ) have been used to screen for genes involved in neuronal growth regulation. At embryonic/ larval stages, genetic screens have mostly been based on analyses of animals bearing mutations that were induced by chemical treatment, radiation or via transposable elements. Morphological read-outs used in these screens have included motornerves, projections in the CNS, or sensory projections in the trunk or head (for example, Bolwig's organ; 1-4 in Figure 1) [23-32]. Some screens have been carried out on adult flies using as read-outs the giant fibre system (13 and 14 in Figure 1) or general brain morphology $[33,34]$. However, since many mutations cause embryonic or larval lethality, the utility of adult animals for genetic screens is limited. To overcome this problem, mosaic strategies have been used in which only specific tissues express the mutant phenotype and can be maintained by an otherwise normal body [13]. Such mosaic screens have been successfully carried out using adult photoreceptor axons as read-outs ( 8 in Figure 1) $[35,36]$. A further refined mosaic strategy is the MARCM technique, in which homozygous mutant neurons can be visualised at the single cell level, surrounded by heterozygous, non-mutant cells [37]. This technique has been used to study and screen for growth aberrations of mushroom body, olfactory and photoreceptor neurons $(8,10$ and 12 in Figure 1) [38-40]. Based on these various screens in embryonic, larval or adult individuals, many mutations that result in defective axon growth have been identified [3]. The gene functions underlying a number of these mutations will be discussed below (see 'Regulators of actin dynamics in Drosophila growth cones' below).
Studies of neurons in situ have the essential advantage that they address the relevance of genetic mechanisms for developmental processes in a natural context. However, the ability to utilise precise and well-controlled pharmacological, physiological or imaging methods in such in situ systems is limited. To address these shortcomings, cultures of primary neurons, obtained from embryonic or larval tissues, have been established in Drosophila. These primary culture systems have been used successfully to demonstrate and/or analyse various phenomena, such as promotion of axonal growth by the neural cell adhesion molecule (N-CAM) homologue Fasciclin 2 or the extracellular matrix molecule laminin [41-43], induction of axonal fasciculation through neuronal activity [44], dependence of axonal growth on endocytosis $[45,46]$, or cAMP-dependent neurotransmitter release from growing neurons [47]. All of these phenomena are likely to be of relevance to neuronal growth in situ $[9,21,48]$, and the established culture systems provide valuable additional means for their study.

Taken together, the Drosophila system provides a wide range of cellular models to be used for studies of axonal growth. In addition, a number of models exist for other forms of neuronal growth, such as dendritic arborisation or the branching and plasticity of synaptic terminals [4952]. However, these systems will not be considered here.

\section{Growth cone dynamics in Drosophila Principal structure and function of growth cones}

The elongation of an axon is led at its tip by a highly dynamic structure, the growth cone, first described and named by S Ramón y Cajal ("cono de crecimiento") and then confirmed in live studies by RG Harrison [53-55]. Growth cones navigate along stereotypical paths, steadily elongating the axon by adding new structural components such as microtubules and membrane to its tip [56]. Just like the leading front of migrating cells, growth cones display actomyosin-containing filopodia and lamellipodia, focal contacts, a dynamic population of microtubules, and cell polarity markers such as Par-3 and -6 [57-62]. In contrast to migrating cells, where stress fibres pull the entire cell forward, neuronal cell bodies generally remain behind when growth cones advance, remaining connected by the steadily elongating axons, the core of which contains bundled, stable microtubules representing the highways for axonal transport.

It has been shown for growth cones of many species, that their guidance requires actin dynamics in the growth cone periphery $[55,59,60,63]$. The peripheral filamentous actin cytoskeleton executes a continuous, myosin-driven retrograde flow that involves ATP-dependent addition of globular actin to actin filaments at their barbed ends (pointing towards the growth cone's periphery), a gradual change of 
actin-bound ATP to ADP, and hydrolysis or severing at their pointed ends (pointing towards the growth cone's centre) [64-66]. This process of actin assembly and disassembly and its organisation into lamellipodial networks and filopodial bundles is regulated by a complex molecular machinery [65,67-69], which we detail below in the context of Drosophila components (see 'Regulators of actin dynamics in Drosophila growth cones').

Whereas growth cone guidance crucially depends on actin dynamics, growth cone advance depends on microtubules. This is clearly demonstrated by the persistence of axonal growth in the presence of actin polymerisation blockers, in vertebrates as well as in Drosophila [55,70-72], whereas pharmacological destabilisation of microtubules causes growth cone retraction [55,73]. Furthermore, extending axons can even be induced to turn in the absence of filamentous actin if they are exposed to an electrical field [74]. Microtubules in the axon shaft and central zone of growth cones are stable and bundled, whereas single unstable microtubules elongate into and retract from the peripheral actin-rich zone in a highly dynamic fashion. These microtubules can be trapped or stabilised through signals in the growth cone periphery, thus determining the direction in which microtubules of the axon shaft will extend [55,58-60,63]. Microtubule growth and shrinkage is, per se, an autocatalytic process [75-77]. However, a number of cellular factors regulate microtubule dynamics, as detailed below in the context of Drosophila components (see 'Regulators of microtubule dynamics in Drosophila growth cones').

\section{Growth cones in Drosophila}

Initial work on Drosophila growth cones dates back more than 20 years when growth cones were first described incidentally in a study on the role of the activity regulator Maleless/Nap in primary neurons cultured from the larval nervous systems [78]. In vivo observations carried out on growth cones of primary neurons in culture demonstrated classifiable shape differences (longer filopodia of ventral ganglion-derived neurons versus those derived from brain), and also established strategies to measure their dynamics [79]. These strategies were later used to demonstrate that genetic or pharmacological alterations of cAMP levels influence growth cone dynamics [80]. Analyses of dye-filled motorneurons in Drosophila embryos demonstrated that their growth cones make characteristic and reproducible directional decisions when advancing in the CNS and periphery [81]. In agreement with this finding, ultrastructural studies in the developing embryonic Drosophila CNS showed that filopodia of pioneering growth cones establish close contacts with characteristic sets of cells in their immediate environment [82]. In vivo studies of the identified RP2 motorneuron in the same context revealed that these growth cones grow at rates comparable to other animal model systems and carry out a set of characteristic shape changes along their reproducible paths [83]. Follow-up studies using this system showed that genetic removal of the Roundabout receptor (see 'Mediolateral patterning of longitudinal fascicles' and 'Growth cone guidance at the Drosophila CNS midline' sections below) in these growth cones led to an increase in the length and persistence of filopodia [84]. In vivo observations on growth cones of a different set of motorneurons (ISNb) demonstrated that their filopodial dynamics and guidance are regulated through GTPases of the Rho-family and their downstream effectors $[85,86]$. Further studies on embryonic motorneurons have shown that growth cones of pioneer neurons display a significantly more complex shape than their follower axons [9], a finding that is consistent with descriptions of the growth cones of pioneer/follower neurons in vertebrates $[87,88]$. In the Drosophila system, this behaviour is regulated by the $\mathrm{N}$ CAM homologue Fasciclin 2 [9]. Motorneuronal growth cones have also been studied in their transition phase into a characteristically shaped neuromuscular junction. Such analyses have revealed how growth cones, which initially explore a wider muscle field, transform into precisely targeted neuromuscular terminals $[89,90]$. Ultrastructural analyses of such growth cones have shown how filopodia of identified motorneurons establish intimate contacts only with their specific target muscles, and that this process is regulated through the presentation of specific cell recognition molecules [91]. Consequently, ablation of such target muscles changes the behaviour of growth cones in their target area [92].

Drosophila growth cones display the characteristic hallmarks of those in other systems, such as highly dynamic filopodia, enrichment of microtubules at their core and the presence of filamentous actin in their periphery (Figure 3). Yet, to date, subcellular studies of Drosophila growth cones are fairly sparse. Most of the insights into axonal growth mechanisms in Drosophila (as reviewed below) have been derived from analyses of the axonal projection defects found in the mature embryonic or adult nervous system in mutant animals or under experimentally manipulated conditions. There are only few descriptions of the behaviours of growth cones during the axon elongation phase in these animals.

Regulators of actin dynamics in Drosophila growth cones The morphological studies of Drosophila growth cones described above ('Growth cones in Drosophila' section) suggest that they possess the same cytoskeletal machinery as found in other model organisms ('Principal structure and function of growth cones' section). In this section we summarise and speculate on the (potential) factors regulating cytoskeletal dynamics in Drosophila growth cones. An overview of these components is given in Figure 3 and 

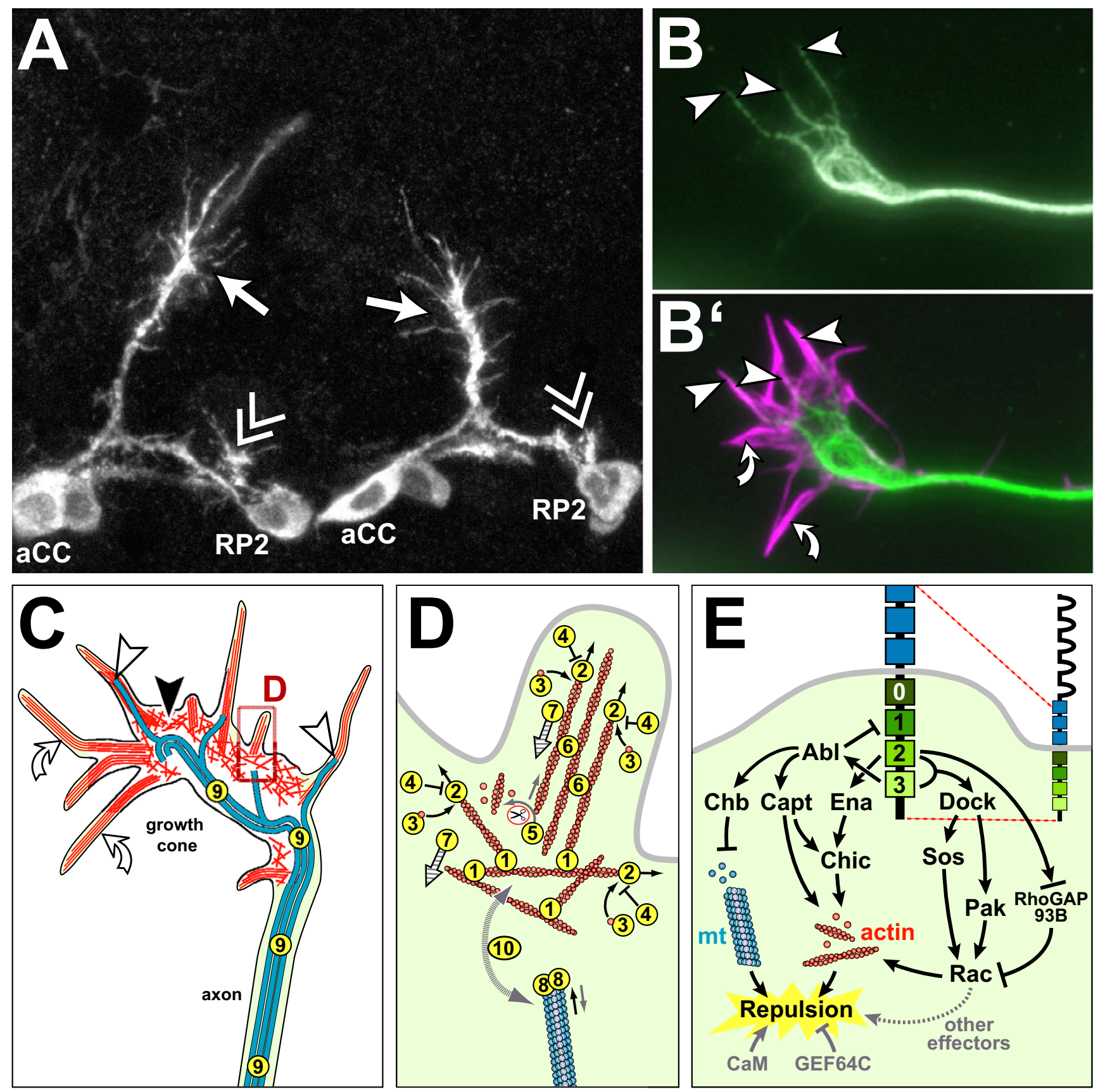

Figure 3 


\section{Figure 3}

Drosophila growth cones and the (potential) factors regulating their cytoskeletal dynamics. (a) Growth cones of aCC (arrows) and RP2 motorneurons (double chevrons; cell bodies named) in two consecutive segments of the trunk of a Drosophila embryo, stained with a cell-specifically expressed membrane marker. (b,b') Cultured Drosophila growth cone stained for microtubules (green) and filamentous actin (magenta); some filopodia lack microtubules (curved arrows), whereas others are deeply invaded (arrow heads indicate microtubule tips). (c) Schematic representation of the cytoskeletal organisation in Drosophila growth cones as extrapolated from work on growth cones in other species (detailed in the section 'Principal structure and function of growth cones'): veil-like lamellipodia (black arrowhead) contain mesh-like networks of actin filaments (randomly oriented red lines), whereas pointed filopodia (white arrowhead) contain bundled actin filaments (parallel red lines); microtubules (blue lines) are bundled in the axon, but single splayed microtubules extend into the periphery of the growth cone (curved white arrows indicate splayed microtubule tips), reaching into filopodia, as was similarly reported for growth cones of other species or migrating cells [63,330]. (d) Details of the boxed area in (c); circled numbers correlate with the numbers in Table I and represent the following molecular activities: I, actin filament nucleation by Arp $2 / 3$ (which subsequently stays with the pointed ends); 2, actin filament nucleation and elongation by formins (which stay with barbed ends); 3, actin monomer binding; 4, barbed-end capping; 5, pointed end-depolymerisation/severing; 6, actin filament bundling; 7, retrograde flow of actin cytoskeleton; 8, microtubule plus end binding; 9, microtubule stabilising; 10, actin-microtubule linkage. Black straight arrows indicate growth of actin filaments or microtubules, grey straight arrows shrinkage, black curved arrows addition of actin monomers, grey curved arrows removal of actin monomers or filamentous fragments, hatched arrows indicate direction of retrograde actin flow, and the grey dashed curved double arrow linkage of actin and microtubules. (e) Current view of the effectors downstream of the Slit receptor Robo mediating repulsion from the midline of the ventral nerve cord. Robo (top right) habours five immunoglobulin domains (half elipses) and three fibronectin type III domains (blue boxes) extracellularly, and four conserved cytoplasmic (CC) domains (light to dark green) intracellularly. Robo induces growth cone repulsion by controlling cytoskeletal dynamics via either Abelson kinase (Abl) and Enabled (Ena), or Rac activity. Ena binds at CC2 and acts most likely through Chickadee/Profilin on actin dynamics. Abl binding to Robo at CC3 influences actin dynamics via Capulet and microtubule dynamics via the +TIP protein Chromosome Bows (Chb/Orbit/MAST). Simultaneously, Abl phosphorylates CCI to antagonise Robo function. The regulation of Rac activity through Robo occurs through $\mathrm{CC} 2 / 3$ recruitment of the $\mathrm{SH} 3-\mathrm{SH} 2$ adaptor molecule Dreadlocks (Dock) which, in turn, activates Rac through both Pak and the GEF Sos. In parallel, active Robo can influence Rac activity via the binding of RhoGAP93B (vilse/CrGAP) to CC2, but it remains unclear whether RhoGAP93B is positively or negatively regulated by Robo. Paradoxically, both decrease and increase of Rac activation levels can cause midline crossing, suggesting that: Rac might influence other effectors to cause repulsion; a precise Rac activation level is required to mediate Slit-induced repulsion; or a sequential modification of Rac in response to Robo activation has to occur, such as an initial role to prevent extension towards the source of the repellent and another role to encourage extension away from the Slit source. Calmodulin and GEF64C have additionally been identified as modifiers of Robo activity, although it is not clear yet how they influence Robo signalling (calmodulin possibly through Chic).

\section{Table 1.}

Several factors have been reported to be able to seed new actin filaments, a process called 'nucleation'. One of these factors is the Arp2/3 (actin-related protein) complex, which is composed of seven subunits. The genes encoding all its subunits have been identified in Drosophila and some of them have been functionally assessed [93,94]. Loss of function of the genes Suppressor of profilin 2 (ArpC1) and/or Arp66B (Arp3) causes severe axonal projection defects when analysed at late embryonic stages (Figure 4, xxxix) [95]. Another independent nucleator of actin filaments, Spire, has been described for Drosophila [96] but seems not to be localised in the nervous system [14]. As opposed to Arp2/3-complex or Spire, members of the Formin family of proteins are nucleators and, in addition, effective barbed end-binding elongators of actin filaments [97]. Of the six Drosophila Formins [98], DAAM (dishevelled associated activator of morphogenesis) is expressed pan-neurally while two others, CG32030 and
CG32138, are specifically expressed within midline glia (the AA142 transposon insertion, a classic midline glia marker, is inserted within CG32030; Richard Tuxworth and GT, unpublished observations). The other Formins, cappuccino, diaphanous and formin3, do not appear to be expressed at detectable levels in developing neurons [98]. No neural phenotypes have yet been associated with mutations in either of these genes, but ectopic expression of Formin 3 in the CNS can induce strong pathfinding phenotypes [98]. Thus, based on our current knowledge, the Arp2/3 complex and DAAM are the potential actin nucleators in Drosophila growth cones. Of these, Arp2/3 is unlikely to regulate subsequent actin filament elongation, since it stays with the pointed ends of elongating actin filaments, which move away from the very cell periphery after nucleation has occurred $[68,97,99]$. Instead other factors have been proposed to facilitate actin filament elongation. Likely candidates in Drosophila are DAAM (see above) or Enabled, the Drosophila member of the Enabled/VASP (vasodilator-stimulated phosphoprotein) fam- 
Table I: Direct regulators of the cytoskeleton with (potential) functions at growth cones

\begin{tabular}{|c|c|c|c|}
\hline Gene name & Common synonyms & Direct regulators & References \\
\hline \multicolumn{4}{|l|}{ Actin filament nucleation and elongation $(1+2)$} \\
\hline Suppressor of profilin 2 (Sop2) & $\mathrm{ArpCl}$ & $\begin{array}{l}\text { WASp (+), SCAR/WAVE } \\
\text { complex (+; containing: } \\
\text { SCAR/WAVE, Hem/kette, Sra- } \\
\text { I/CYFIP, Abi, SIPI/HSPC300) }\end{array}$ & {$[95,149]$} \\
\hline Actin-related protein 66B (Arp66B) & Arp3 & & \\
\hline Arp / 4D, Arc-p34, Arpc3A/3B, Arc-p20, p/6-Arc & Arp2, ArpC2-C5 & & {$[93,94]$} \\
\hline dishevelled associated activator of morphogenesis (DAAM) & NA & $?$ & $*$ \\
\hline enabled (ena) & ENA/VASP & Abelson (-), Dlar (+) & {$[100,101,164]$} \\
\hline \multicolumn{4}{|l|}{ Actin monomer binding (3) } \\
\hline capulet (capt) & $a c u, C A P$ & Abelson (+) & {$[103]$} \\
\hline ciboulot (cib) & NA & ? & {$[102]$} \\
\hline chickadee (chic) & profilin, sand & ena $(+)$ & {$[101,164]$} \\
\hline twinfilin (twf) & NA & ? & {$[104]$} \\
\hline \multicolumn{4}{|l|}{ Barbed-end capping (4) } \\
\hline capping protein $\alpha$ (сpa) & NA & ? & [109] \\
\hline capping protein $\beta(c p b)$ & NA & $?$ & [333] \\
\hline \multicolumn{4}{|l|}{ Pointed-end depolymerisation/severing (5) } \\
\hline twinstar (tsr) & ADF/cofilin & LIMKI (-), ssh (+) & {$[111]$} \\
\hline flightless I (flil) & (gelsolin family) & ? & {$[115]$} \\
\hline quail (qua) & villin-related (gelsolin family) & $?$ & {$[116]$} \\
\hline \multicolumn{4}{|l|}{ Actin filament bundling (6) } \\
\hline singed (sn) & fascin & $?$ & {$[126]$} \\
\hline$\alpha$ Actinin (Actn) & flightless $A$ & $?$ & {$[128]$} \\
\hline Fimbrin (Fim) & NA & $?$ & [334] \\
\hline cheerio (cher) & filamin & $?$ & [129] \\
\hline \multicolumn{4}{|l|}{ Retrograde flow of filamentous actin (7) } \\
\hline zipper (zip) & myosin heavy chain & $?$ & {$[121]$} \\
\hline spaghetti squash (sqh) & myosin II light chain & $\begin{array}{l}\text { Strn-Mlck (+), Mbs/myosin } \\
\text { phosphatase (-) }\end{array}$ & {$[119,120]$} \\
\hline \multicolumn{4}{|l|}{ Microtubule plus end binding (+TIPs) (8) } \\
\hline CLIP-I 90 & NA & $?$ & {$[152]$} \\
\hline chromosome bows (chb) & CLASP, Orbit/MAST & Abelson $(+)$ & {$[153]$} \\
\hline ebl, CGI8190, CG3237I & NA & $?$ & {$[155]$} \\
\hline APC-like $(A p c)$ & Apcl & $?$ & [154] \\
\hline Apc2 & NA & $?$ & {$[154]$} \\
\hline \multicolumn{4}{|l|}{ Microtubule stabilising (9) } \\
\hline futsch & $M A P I B, m A B 22 C I 0$ & Fmr I/fragileX/fmrp (-) & {$[163,335]$} \\
\hline tau & NA & ? & {$[161]$} \\
\hline \multicolumn{4}{|l|}{ Microtubule-actin linkage ( 10$)$} \\
\hline short stop (shot) & kakapo, groovin & $?$ & {$[168]$} \\
\hline pod-I & NA & $?$ & {$[169]$} \\
\hline
\end{tabular}

The table lists official gene names according to FlyBase [14] (first column), examples of commonly used synonyms (second column; NA, not applicable), molecules reported to regulate the respective gene/protein directly (third column; '+', activating; '-', down-regulating), and representative references (fourth column; for more information refer to FlyBase; preferentially those references are listed that link to the nervous system). Bold headings indicate a functional assignment of the factors listed below, and numbers refer directly to the circled numbers in Figure 3. *See section 'Regulators of actin dynamics in Drosophila growth cones' for more detail. 
ily of proteins, which is a direct target of the cytoplasmic Abelson tyrosine kinase in the context of neuronal growth $[100,101]$. Further factors regulating actin assembly are molecules that bind monomeric actin, such as Capulet, Ciboulot and Profilin/Chickadee, all of which are essential for neuronal growth regulation in Drosophila [101103]. A further actin monomer-binding molecule, Twinfilin, is likely to be expressed in the nervous system, but no data exist concerning its cellular function [104].

Profilin/Chickadee has been shown to interact with Calmodulin [105], suggesting $\left[\mathrm{Ca}^{2+}\right]_{\mathrm{i}}$ may influence its activity. Consistent with this observation, growth cones of Drosophila, like those of other species, show measurable changes in local calcium concentration [106-108]. Barbed-end capping proteins are typical inhibitors of actin polymerisation. For Drosophila, the capping proteins $\mathrm{Cpa}$ and $\mathrm{Cpb}$ have been reported, but their role in the nervous system has yet to be addressed [109].

While actin filaments elongate at their barbed ends, they are severed and/or depolymerised at their pointed ends, and a number of factors have been assigned to this process [110]. One of these factors is $\mathrm{ADF} /$ cofilin (Twinstar in Drosophila), the activity of which is directly regulated by LIM kinase and the Slingshot phosphatase in vertebrate growth cones and the developing Drosophila nervous system alike [111-113]. Another group of potent filamentous actin severing molecules comprises members of the gelsolin family [114], at least two of which have been identified in Drosophila, flightless I and quail $[115,116]$. However, nothing is known about their potential requirement for axonal growth.

Distal elongation and proximal shortening of actin filaments, generally referred to as 'treadmilling', would potentially lead to a constant outward movement of actin filaments. However, such movement is antagonised by myosin motor proteins, which produce a steady retrograde/reaward flow of the actin network. This action of myosin II plays an important regulatory role downstream of guidance-related signalling events $[58,117,118]$. Accordingly, two subunits of non-muscle myosin, the heavy chain (Zipper) and the regulatory light chain (Spaghetti-squash), and the direct regulators myosin light chain kinase (MLCK) and myosin light chain phosphatase have been implicated in neuronal growth in Drosophila [119-121].

Accumulating evidence suggests that the set of actin regulators involved in lamellipodia formation (producing branching networks of filamentous actin) is not congruent to those in filopodia (bundled linear actin filaments) [69]. The typical parallel bundling of actin filaments in filopodia can be initiated by the actin polymerisation fac- tor Enabled/VASP in collaboration with Formins $[122,123]$, and the principle involvement of both these factors in axonal growth of Drosophila has been reported (see above). Another suggested mode of filopodium formation is through bundling of filamentous actin via the powerful cross-linker Fascin $[124,125]$. Singed, the Drosophila orthologue of Fascin, has been shown to influence neuronal growth [126]. Other factors cross-linking actin filaments, such as $\alpha$ Actinin, Fimbrin or Filamin (cheerio in Drosophila) are able to substitute Fascin in the context of Listeria propulsion [127]. In Drosophila, $\alpha$ Actinin is expressed in the developing CNS [128], and cheerio has been associated with associative learning [129], but none of these factors has been studied in the context of neuronal growth so far [14].

The complex machinery mediating actin dynamics in growth cones is essentially orchestrated by Rho-family GTPases [130,131], six of which have been reported for Drosophila. Of these, Rac1, Rac2 and Mtl have an overlapping requirement during the regulation of axon extension, branching and guidance (Figure 4, xxxvi and xxxvii) $[132,133]$. Cdc42 is similarly involved in growth cone guidance, but its functions appear to involve downstream effectors different from those of Rac1 (for example, Pak) $[85,86,134]$. RhoA has been shown to inhibit neuronal growth in Drosophila [135], whereas little is known about the other two Rho-like GTPases, RhoL and RhoBTB [136]. Many of the factors shown to act up- or downstream of Rho-GTPases in vertebrates have been identified in Drosophila and their functions in neuronal growth were revealed by their mutant phenotypes. Thus, GTPases are active in a GTP-bound state, promoted by RhoGEFs (guanine nucleotide exchange factors), and inactive in a GDPbound state, catalysed by RhoGAPs (GTPase activating proteins) [131]. The Drosophila genome contains 20 predicted RhoGAPs and 22 RhoGEFs [137-139]. At least three RhoGEFs, Still life, Gef64C and Trio, have been associated with neuronal growth regulation of the axons of motorneurons, photoreceptors, and neurons in the ventral nerve cord (Figure 4, xxxviii) [138,140-142]. Three of the 20 RhoGAPs, RhoGAP-71E1, RhoGAP-50C14 and RhoGAP-16B12/p190, show neuronal growth phenotypes when assayed in the mushroom body neuropile (MB in Figure 1d) [139], and RhoGAP93B/CrGAP/Vilse is involved in midline crossing of axons (see 'Growth cone guidance at the Drosophila CNS midline' below) $[143,144]$. An involvement in neuronal growth regulation has also been demonstrated in various cellular contexts for typical effectors of Rho-like GTPases, such as p21-activated kinase (PAK) and its closely associated partner, the $\mathrm{SH} 2 / \mathrm{SH} 3$ adaptor protein Nck (Dreadlocks = Dock in Drosophila), the RhoA effector Rho-kinase (Drok or Rock in Drosophila), and the Cdc42 effector WASP, a direct activator of the Arp2/3 complex [95,141,145,146]. WASP's par- 


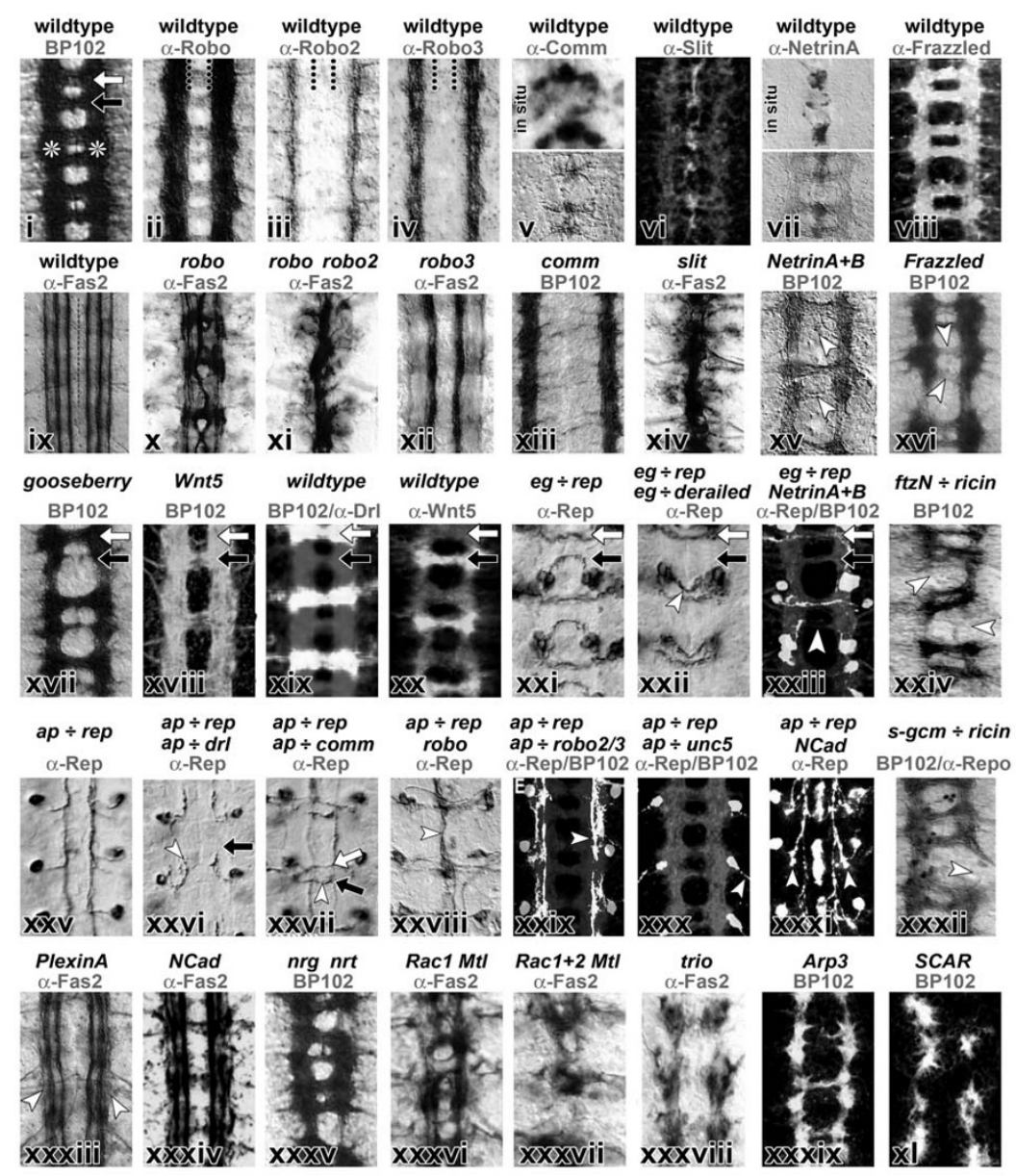

\section{Figure 4}

Representative embryonic mutant phenotypes of axonal projections in the ventral nerve cord. Images of ventral nerve cords in horizontal view (dorsal up) of embryos that are wild type, mutant or display targeted expression of genes in subsets of neurons. Genotypes are indicated in black at the top, antibody stainings in grey (abbreviations: Robo, Roundabout; Comm, Commissureless; Fas2, Fasciclin 2; Drl, Derailed; Rep, reporter gene; eg, eagle; ftz, fushi tarazu; ap, apterous; unc5, uncoordinated 5; NCad, N-Cadherin; gcm, glia cells missing; nrg, neuroglian; nrt, neurotactin; "X $\div$ Y", expression of gene $Y$ driven by the promoter of gene X). BPI02 antiserum labels the complete neuropile (i), consisting of two connectives (asterisks) and, per segment, an anterior (white arrow) and posterior (black arrow) commissure. At stage 16 Fasciclin 2 labels three prominent longitudinal fascicles per connective (ix). (ii-viii) Expression patterns of genes involved in midline crossing and, below (x-xvi), respective lossof-function phenotypes (see text for details). (xvii-xxii) Regulation of growth through the anterior versus posterior commissure, with loss of posterior (xvii) or anterior (xviii) commissure, specific expression of Derailed (xix) in anterior and its ligand Wnt (xx) in posterior commissure, and shift of posterior commissure neurons (eagle-Gal4; $x \mathbf{x i})$ to the anterior commissure (white arrow head in xxii) upon Derailed expression in their axons. (xxiii) Same eagle-Gal4 neurons partially lack commissural projections in netrin $A+B$ mutant background (compare white arrowhead in (xv)). (xxv-xxxi) Detailed phenotypic studies using identified apterous-Gal4 neurons, which project transversely to the medial connectives where they form a longitudinal fascicle $(x x v)$; as indicated by white arrows, they stall prematurely upon Derailed expression (xxvi), project across the midline upon Comm expression (xxvii), collapse towards the midline in robo mutant background (compare $x$ ), shift to lateral positions upon Robo2+3 expression ( $x$ xix), project out of the CNS upon Unc5 expression ( $x x x)$, or turn prematurely from transverse into longitudinal direction in $\mathrm{N}$-cadherin mutant background (xxxi). (xxiv, xxxii). Connectives are affected upon ablation of longitudinal pioneer neurons (xxiv) or longitudinal glia cells (xxxii). (xxxiii-xl) Various neuropile phenotypes in embryos mutant for transmembrane molecules (xxxiii-xxxv) or factors involved in cytoskeletal regulation (xxxvi-xl). Images were taken, with permission, from [24I] (i, xxxv), [253] (ii-iv, xii, xxix), [207] (v, top), [33l] (v, bottom), [259] (vi), [266] (vii, xv), [225] (viii), [244] (ix, xxxiii), [27I] (x, xi, xiv), [23] (xiii, xvii), [2I2] (xvi, xxx), [263] (xviii), [208] (xix, xxi, xxii, xxv-xxvii), [332] (xx), [267] (xxiii), [219] (xxiv), [277] (xxviii), [226] (xxxi, xxxiv), [223] (xxxii), [132] (xxxvi-xxxviii), [95] (xxxix, xxxx). Images were modified to grayscale and adapted to size. 
alogue SCAR in itself is not an immediate effector of GTPases, but the WAVE/SCAR complex (containing SCAR, CYFIP, Kette, Abi and HSPC300) can be targeted by Rac through its direct interaction with CYFIP $[147,148]$. The WAVE/SCAR complex activates the Arp2/3 complex and has a clear impact on neuronal growth (Figure $4, \mathrm{xl}$ ) $[95,149]$.

Taken together, most if not all classes of actin regulatory factors have been identified in Drosophila and many of them have been associated to varying degrees of certainty with neuronal growth.

\section{Regulators of microtubule dynamics in Drosophila growth cones}

The second cytoskeletal component essential for growth cone advance is the microtubule; factors regulating their dynamics are summarised in Figure 3 and Table 1. One important class of proteins regulating the elongation and shortening of microtubules comprises the plus-end-tracking molecules (+TIPs) $[150,151]$. A number of these have been identified in Drosophila. CLIP-190 (orthologue of vertebrate CLIP-170) is strongly expressed in the nervous system [152] and has been shown to interact with the +TIP protein Chb (Chromosome bows/Orbit/MAST, an orthologue of vertebrate CLASP, CLIP-associated protein) [153]. Further +TIP molecules described for Drosophila are APC1 and APC2 (adenomatous polyposis coli), both of which are expressed in the brain (though mainly in neuronal somata) [154], and three possible homologues of EB1 (Endbinding protein 1;Eb1, CG18190, and CG32371), the potential role of which has yet to be addressed in the nervous system [155]. A potential regulator of these molecules is the Par3/6-complex, which localises to growth cones in both mammals and Drosophila, and has been shown to organise the cytoskeleton in Drosophila motorneurons $[19,57,156,157]$. Another molecule required for neuronal growth in Drosophila is the lissencephaly-associated factor Lis1, a molecule shown to be capable of binding microtubules to reduce microtubule catastrophe events $[158,159]$. Characterisation of the lis1 mutant growth phenotype in Drosophila suggests Lis1 may function through an interaction with the motor protein Dynein $[158,160]$. Finally, an important class of microtubule-binding proteins, also reported for Drosophila, comprises the microtubule associated proteins (MAPs), which stabilise and facilitate transport along microtubules [151]. MAP2 seems to be absent from the Drosophila genome, but one Drosophila Tau-like protein that localises within axons has been described, although no functional data have been reported to date [161,162]. A MAP1B-like molecule called Futsch has been shown to regulate axonal growth in Drosophila, presumably through stabilisation and loop formation of microtubules [163].
Therefore, as for the actin cytoskeleton, many regulators of microtubule dynamics in the Drosophila nervous system have been identified. Interestingly, the proteins described here are regulated in part through the same factors described previously in relation to actin dynamics. For example, the activity of the +TIP protein Chb/CLASP is regulated by the tyrosine kinase Abelson during axon guidance at the CNS midline [153], which is also a regulator of the actin filament elongating factor Enabled/VASP [164]. Furthermore, GTPases of the Rho-family, which are major regulators of the actin cytoskeleton (see 'Regulators of actin dynamics in Drosophila growth cones' above), also influence a number of microtubule regulating molecules $[150,156]$.

\section{Regulators of actin-microtubule cross-talk}

Cross-talk between microtubules and actin is an essential aspect of regulation of growth cone behaviour (see 'Principal structure and function of growth cones' above), and this process has long been known to be facilitated by microtubule-associated proteins [165]. Such a function may, in part, be carried out by MAPs, as suggested by the observation that MAP2 can bind both microtubules and actin [166]. In Drosophila, two molecules with dual actinand microtubule-binding capabilities have been reported. Short stop/Kakapo is a member of the Spectraplakin family of cytoskeletal linker molecules [167], and its cytoskeletal binding activity is required for axon extension [168]. Another actin-microtubule linker in Drosophila is the highly conserved DPod-1, which has been suggested to be required for growth cone guidance rather than axon extension [169].

In conclusion, many (potential) components of the machinery regulating the cytoskeletal dynamics of growth cones have been identified and characterised to differing degrees in Drosophila. It is essential to extend the analysis of these factors both at the subcellular level and in combination with genetic strategies, using the various growth cone models available in Drosophila to identify precisely how guidance cues are transduced to direct cytoskeletal reorganisation.

\section{Signalling mechanisms involved in axonal pathfinding in Drosophila \\ Nature of axon guidance cues}

Cytoskeletal regulation is a house-keeping function required in all cells and, thus, a large common set of molecules serving this purpose would be expected to be present in all neurons. In contrast, the signals involved in growth cone guidance and/or the molecular mechanisms that transduce those signals are likely to differ between different types of neurons, as each neuron makes a specific set of pathfinding decisions to reach its synaptic target. It follows that the neuronal cytoskeletal machinery should 
be responsive to a broad spectrum of axon guidance cues and signalling pathways. Factors that have been shown to guide growing axons include simple structural barriers such as impenetrable tissues or gaps due to wounding [170], electric fields (galvanotropism) [171,172], light (phototropism) [173], or mechanical forces (stereotropism) that can be either applied externally $[174,175]$ or generated via the growth cone's own pulling forces antagonised by adhesive interactions with the environment [176]. However, the best understood form of axon guidance is through external chemical/molecular cues and their receptive machinery within growth cones. Many ligand/receptor pathways involved in axon guidance have been identified [177-179]. Guidance molecules can be either diffusible, or attached to the extracellular matrix or cell surfaces. They are present in the environment of growth cones in an evenly distributed, graded or spatially restricted manner. Depending on its receptive machinery, a growth cone may either fail to respond to certain guidance molecules, or interpret them as growth-permissive, attractive or repulsive signals [2]. It is now a universally accepted idea that the same guidance molecules can act both as repellents and attractants on different axons, as was shown for ligands such as Unc-6/Netrin or Semaphorins in invertebrates and vertebrates alike [180-183]. To add to this complexity, the behaviour of an individual growth cone can be modified over time, for example, through alterations in its electrical activity patterns $[184,185]$.

In the following, we will focus on a subset of neuronal model systems studied in Drosophila to illustrate the complexity of the molecular signalling pathways discovered and analysed in this model organism.

\section{Pathfinding in the trunk of the Drosophila embryo \\ Axons of motorneurons and sensory neurons}

A variety of neuronal model systems have been used for studies of axonal growth in Drosophila (see 'Models for axonal growth in Drosophila' above; Figure 1). Of these, the most intensely studied are the systems in the trunk of the Drosophila embryo, in particular, motoraxons in the periphery and axons of motor-, inter-, and sensory neurons within the CNS (neurons 1-3 in Figure 1). From developmental and morphological analyses of these neurons, it has become clear that the identity of individual neurons is specified mainly by their stereotypic lineages [186-188]. Each neuron then makes a number of stereotypic pathfinding decisions as they advance to their particular target and the mature morphology of many of these axons have been characterised (Figure 5c,d) [189-193].

For example, motorneuronal growth cones make a series of choices as they grow into the periphery. First, they have to take the appropriate stepwise decisions that guarantee that their axons exit the CNS and join one of six possible principal nerve branches leading to their appropriate target muscle fields. Second, they defasciculate from other axons in their nerve at precise points to approach their appropriate target muscles. Third, they establish adhesive contacts with their appropriate target muscles at precise positions. Fourth, the motorneuronal growth cones eventually undergo drastic morphogenetic changes and differentiate into neuromuscular junctions. In this cellular system, we currently have insights into: the specification of motorneuron and muscle identities (which in turn determine motor axonal pathfinding behaviour); relevant cells and tissues used as guideposts by motor neurons; mechanisms of fasciculation, defasciculation and pioneer guidance; and the combination of permissive, attractive or repulsive molecular guidance cues governing motor axonal navigation. The systems utilised for studying motor axon guidance and the mechanisms they have revealed are discussed in detail elsewhere $[49,194]$.

In contrast to the motoraxonal system, the sensory system of the trunk has been somewhat neglected, in spite of its obvious advantages, which include the following. First, each of the approximately 40 sensory neurons per hemisegment has been individually identified [195]. Second, sensory cell bodies are relatively accessible and can be visualised at the single cell level in the living embryo [192]. Third, the normal pattern of axon growth from several of these neurons, and the environment through which they navigate in the periphery and where they terminate in the CNS, have been characterised in detail [192,196-201], providing an ideal background for studies of the genetic control of sensory axon growth. While at least two morphological screens have been performed to uncover such genes [25,30], our understanding of the molecular basis for sensory axon guidance is still limited. Nonetheless, several factors that guide motor axons in the periphery and interneuronal axons in the CNS have been shown to play a role in sensory axon guidance, such as Delta and its receptor Notch [197], the actin-microtubule linker molecule Short stop/Kakapo [25,202], Slit and its cognate receptors Robo and Robo2 [203], and the secreted Semaphorin, Sema2a and its receptors Plexin B and Plexin A [204].

\section{Principal axonal pathfinding decisions in the CNS}

Motor-, sensory and interneurons all extend axons within the CNS. To study their growth decisions in the embryonic CNS, a number of visualisation strategies have been used, comprising global neuropile markers (Figure 4, i) [23], molecular markers for reproducible axon fascicles, such as Fasciclin 2 (Figure 4, ix) [205,206], transplantation-based analyses of neural lineages (Figure 5c,d) [207], labelling of identified neurons through dye injections or 

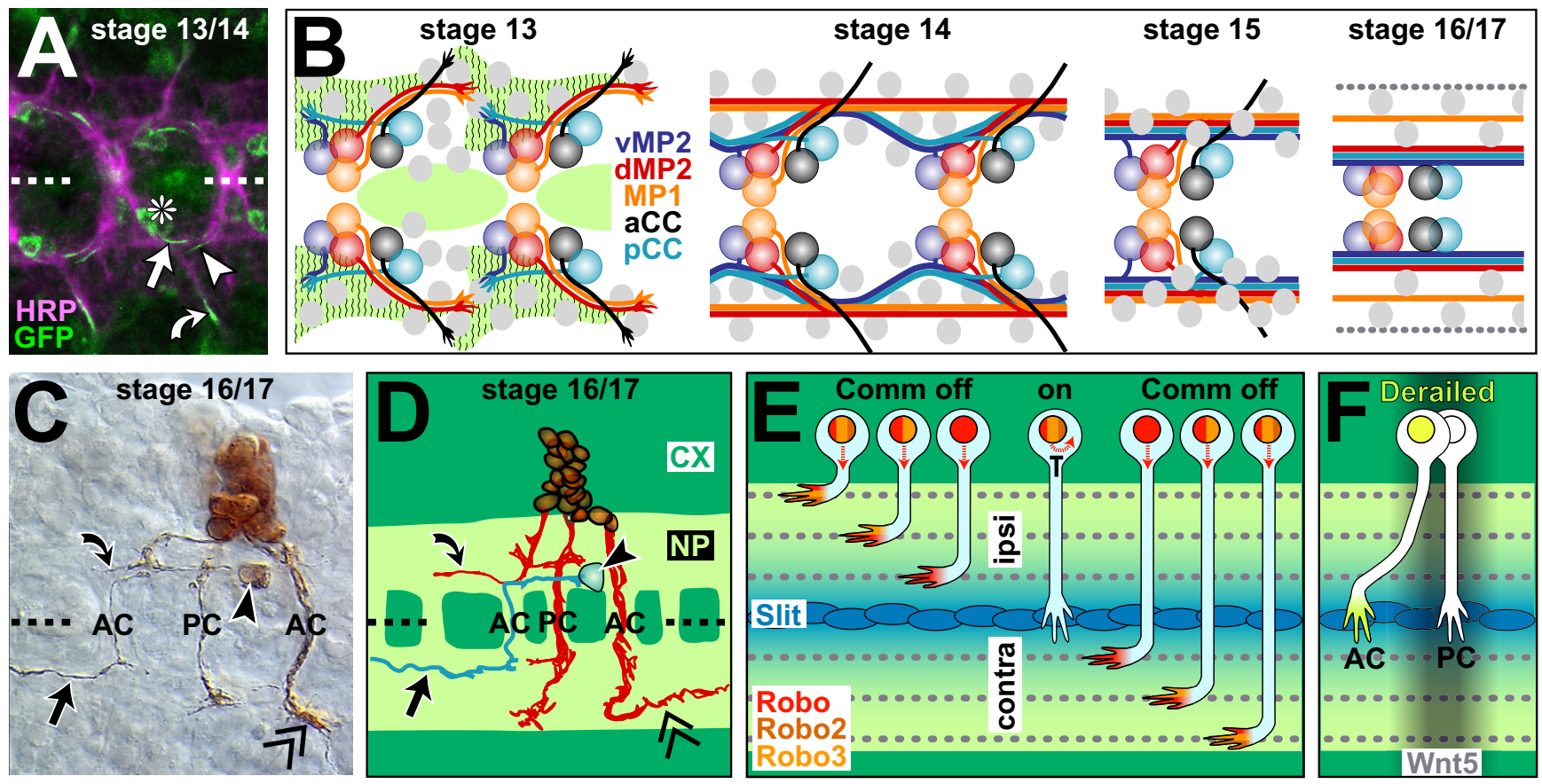

\section{Figure 5}

Axonal pathfinding and fasciculation behaviour in the embryonic ventral nerve cord. (a) In the ventral nerve cord of stage I3/ 14 embryos, growth cones of identified neurons (aCC, curved arrow; pCC, arrow; RP2, arrow head) navigate in stereotypic positions (stippled line, midline; asterisk, somata of $\mathrm{aCC}$ and $\mathrm{PCC}$ ). (b) Schematic representations of early growing neurons VMP2, dMP2, MPI, aCC and PCC (colour coded): at stage 13, their axons are partly guided by glia cells (grey circles) and Netrin A and B (light green) bound to lateral fields of Frazzled expression (wave pattern); MPIs and dMP2s grow jointly posteriorward, whereas VMP2s and $\mathrm{PCC}$ fasciculate and grow together anteriorward until all four neurons contact one another midway between adjacent neuromeres and establish a single longitudinal fascicle (stage I3) that splits (stage I4), re-fasciculates (stage I5) and splits again (stage 16), partly mediated by glia cells ( $\mathrm{pCCs,} \mathrm{dMP2s,} \mathrm{vMP2s} \mathrm{form} \mathrm{a} \mathrm{common} \mathrm{fascicle} \mathrm{close} \mathrm{to} \mathrm{the}$ midline, MPIs a distinct axon tract further lateral; grey stippled line represents the lateral Fas2 fascicle of unknown identity; compare Figure 4, ix). (c,d) The neuroblast lineage NBI-2 [190] illustrates the stereotypic pathfinding choices of individual neurons (curved arrow, ipsilateral longitudinal path; AC/PC, anterior/posterior commissure; arrow, medial contralateral longitudinal; double chevron, lateral contralateral longitudinal; arrow head, soma of identified TB neuron; CX, cortex; NP, neuropile). (e) Regulation of midline crossing and mediolateral longitudinal path choice: ipsilateral neurons don't express Commissureless (Comm), and their combinatorial Robo receptor code determines the mediolateral positioning of their axons; contralateral neurons express Comm (black T), thus preventing transport of Robo receptors to the growth cone (curved red arrow); subsequent downregulation of Comm activity permits the Robo-mediated fascicle choice. (f) Choice of anterior versus posterior commissure during midline crossing is partly determined by posterior expression of Wnt5 (Figure 4, xx), which repels growth cones of Derailed expressing neurons. (c,d) Kindly provided by Janina Seibert, Christoph Rickert and Gerd Technau; (b) redrawn from Hidalgo and Booth [223].

via genetically targeted markers (Figure 4, xxi-xxxi) $[81,208]$, or ultrastructural analyses [8]. The level of precision provided by each of these techniques varies significantly, which can make it difficult to compare studies obtained via different strategies. However, when combining the various approaches, a very precise view of neuronal growth processes in the embryonic Drosophila ventral nerve cord has been obtained, as outlined below.

One obvious feature of axonal growth behaviour in the CNS is that projections of motor-, inter- and sensory neurons aggregate into a cell body-free region, the neuropile, in which synaptic contacts will be established (Figure 2a). This behaviour of neurites to segregate away from cell bodies and constitute the neuropile seems to be driven by axo-axonal affinity, as illustrated by axons of larger groups of neurons in primary cell culture, which always associate into small neuropile-like arrangements [44]. The neuropile stereotypically forms in the dorsal plane of the ventral nerve cord (Figures $1 \mathrm{~b}$ and $2 \mathrm{a}$ ), where many of the pioneer motor- or interneurons that initiate formation of the neuropile are located. In contrast, motor- and interneurons in ventral or lateral positions of the nerve cord, as well as sensory neurons entering through the segmental 
nerves, have to grow through the cortex towards the neuropile. On their way towards the neuropile, axons of neurons derived from the same neuroblast lineage tend to fasciculate $[189,190]$, a property that is also true for the larval nerve cord [209].

Within the (prospective) neuropile, growth cones are faced with a number of decisions (Figures $1 \mathrm{~b}$ and $4 \mathrm{c}, \mathrm{d}$ ). They may first simply terminate shortly after entering the ipsilateral neuropile (some interneurons); second, grow towards a peripheral nerve root to exit the neuropile (ipsilaterally projecting motorneurons); third, turn anteriorly or posteriorly to project along longitudinal fascicles in the connectives (see 'The formation of longitudinal fascicles in the embryonic ventral nerve cord' below; almost all sensory axons and some interneurons); or fourth, cross the midline (see 'Growth cone guidance at the Drosophila CNS midline'; most interneurons and some motorneurons). Those axons that cross the midline are faced with the first and third choices again on the contralateral side. Those axons that do not leave the neuropile terminate their growth in stereotypic positions, presumably at points of future synapse formation [210].

\section{Motoraxonal growth towards the CNS exit point}

The third and fourth growth decisions outlined above (choice of longitudinal fascicles and midline crossing) have been studied extensively during the past two decades, and insights gained from these studies will be reviewed in detail in the sections 'The formation of longitudinal fascicles in the embryonic ventral nerve cord' and 'Growth cone guidance at the Drosophila CNS midline' below. In contrast, virtually nothing is known about the mechanisms underlying axonal growth termination in the neuropile. In the context of the navigational capability of motorneuronal growth cones to exit the CNS, the involvement of only two signalling pathways has been suggested so far: the diffusible ligands Netrin $\mathrm{A}+\mathrm{B}$ and their receptors Unc5 and Frazzled, and the receptor tyrosine kinase Eph and its ligand Ephrin. Targeted expression of Unc5 or of double stranded Eph or Ephrin RNA in interneurons causes their aberrant exit from the CNS (Figure 4, $\mathrm{xxx}$ ) [211,212]. However, later analyses using unc5 and Eph loss-of-function mutations failed to detect equivalent axonal phenotypes, calling the original findings into debate $[213,214]$. At the cellular level, detailed analyses of the contralaterally projecting motorneurons RP1 and RP3 have revealed that their growth cones depend on the presence of the somata of their contralateral homologues, which are required as stepping stones to continue normal pathfinding towards the neuropile exit points. In contrast, ablation studies have revealed that intimate contacts established by these motorneurons with a number of glial guide post cells are not required [81,82,215]. If RP3 motorneurons are prevented from crossing the midline experimentally (axotomy) or genetically (commissureless mutant background; see below), their growth cones will carry out the normal growth regime, however, in mirror image fashion on the ipsilateral side, demonstrating that midline crossing is not an essential prerequisite for their capability to exit the CNS [216,217]. Obviously, the RP3 cell body (ipsi- or contralaterally) lies in a strategic position from which the pathfinding cues towards the exit point can be reached. However, under normal conditions, early growth cones of these motorneurons seem first to be attracted exclusively towards the midline, which dominates over all other pathfinding cues.

\section{The formation of longitudinal fascicles in the embryonic ventral nerve cord The formation of longitudinal fascicles}

Detailed analyses of the developing ventral nerve cord have revealed the time course of initial antero-posterior axonal growth within the longitudinal connectives $[8,82,218,219]$. These investigations demonstrated that a small number of early ipsilateral interneurons, namely MP1, dMP2, vMP2 and pCC, pioneer a scaffold of longitudinal fascicles that are subsequently joined by other ipsi- and contralateral axons projecting in anterior or posterior directions (Figure 5a,b). Cell-specific ablations of MP1, dMP2, vMP2 and pCC in various combinations have demonstrated that these pioneer axons are indeed essential for the establishment of connectives as a whole (Figure 4, xxiv) [219,220].

During their initial advance, growth cones of MP1, dMP2, vMP2 and pCC establish intimate contacts with longitudinal/interface glia cells, which line up in the area of the future connectives prior to the axonal growth phase (Figure $5 b)[8,206,218,221]$. These intimate axono-glial contacts reflect an essential role of this glial population as guidepost cells for the four pioneer neurons, since ablation of these glia cells causes severe disruption of the pioneer neurons' pathfinding and subsequent establishment of connectives (Figure 4, xxxii) [222,223]. Additional guidance cues for early pioneer neuron growth are the secreted factors Netrin A and Netrin B. Both these proteins are released from midline glia cells and become bound in restricted dorso-lateral areas of the ventral nerve cord by neurons in these areas that express Frazzled (a member of the DCC immunoglobulin subfamily; Deleted in colorectal cancer) on their dorsal surfaces (Figure 5b) [224]. Frazzled is able to bind Netrins in these lateral areas, since it is one of two identified Netrin receptors [225]. This distribution of presented Netrins is used as a navigational cue by outgrowing pioneer neurons, as was demonstrated for dMP2 [224]. Thus, Frazzled acts in a non-autonomous fashion in the context of longitudinal pioneer growth. Whether it is also the receptor used by the pioneering growth cones has not been explored [224]. 
In addition to responding to external cues such as glial surfaces and Netrins, the axons of the four pioneer neurons interact with each other in a stereotypical way, involving sequential steps of fasciculation, defasciculation and refasciculation (details in Figure 5b) $[219,223]$. Two factors seem essential for this complex fasciculation behaviour. First, defasciculation of axonal tracts depends crucially on longitudinal glial cells [223], potentially through physical intercalation of glial protrusions. Second, CAMs are expressed on longitudinal axons in a dynamic fashion and are believed to be the immediate factors regulating selective fasciculation processes. These CAMs comprise N-Cadherin [226], Neurotactin (bearing a catalytically inactive cholinesterase-like domain) $[227,228]$, the GPI-anchored molecules Fasciclin 1 (composed of four Fasciclin 1 domains) [229], Connectin (containing leucin-rich repeats) $[230,231]$, and the three immunoglobulin family members Neuroglian (orthologue of vertebrate L1), Fasciclin 2 (orthologue of vertebrate N-CAM) and Fasciclin 3 [232-235]. Of these, NCadherin is strongly expressed throughout the neuropile and its loss causes aberrations of longitudinal fascicles (Figure 4, xxxiv) [226]. Fasciclin 2 is initially expressed only in the pCC pioneer neuron (and its sibling aCC) [234], but its expression gradually spreads to further neurons, constituting a final number of at least 11 longitudinal Fasciclin 2-positive axon tracts in the mature embryonic ventral nerve cord (Figure 4, ix) [236]. In the absence of Fasciclin 2, the selective fasciculation behaviour of the pioneer neurons is considerably impaired, although this does not have other obvious developmental consequences $[8,206]$. An explanation for this mild phenotype seems to be redundancy of factors involved in axonal pathfinding, as best exemplified by Neurotactin. Neurotactin acts as a homophilic CAM in cell culture assays, but this interaction requires its heterophilic binding to the secreted immunoglobulin protein Amalgam [237-240]. Both ligand and receptor are widely expressed in the developing nervous system, but their absence causes no serious detectable phenotypes. However, neurotactin mutant phenotypes emerge in combination with mutations in other neuronal growth-related genes [241]. Thus, embryos carrying loss-of-function mutations of both neurotactin and neuroglian display fasciculation defects of dMP2 and MP1 axons and disrupted connectives at high frequency (Figure 4, xxxv) [241]. Further strong neurotactin mutant phenotypes were revealed in combination with mutations of genes encoding the receptor tyrosine kinase Derailed, the cytoplasmic tyrosine kinase Abelson, or the CAM-like molecule Kekkon, but not with a number of other tested factors (Ptp69D, Ptp99A, Fasciclins 1-3, Pollux and Neuromusculin) $[241,242]$.
As illustrated by neurotactin's genetic interactions, the range of molecules involved in longitudinal guidance of central axons in Drosophila clearly goes beyond adhesion factors, and this is supported by a number of further mutant phenotypes. For example, lack of the transmembrane protein Semaphorin-1A and its receptor PlexinA causes disruption of a lateral Fasciclin 2 tract (Figure 4, xxxiii), whereas lack of PlexinB (the Semaphorin-2A receptor) causes defasciculation of a median Fasciclin 2 tract [243-245]. Selective manipulations of $\left[\mathrm{Ca}^{2+}\right]_{i^{-}}$ dependent Calmodulin function in the four pioneer neurons affect both their growth ability and fasciculation behaviour [246]. Embryos carrying mutations in the genes wnt5 or glaikit (encoding a phospholipase D superfamily protein) show severe disruption of connectives and strong defasciculation phenotypes $[247,248]$. Also, embryos lacking Kuzbanian, a secreted metalloprotease of the ADAM family, or the two receptor-linked protein tyrosine phosphatases Ptp10D and Ptp69D, show severe aberrations of the neuropile. However, in these latter two cases the aberrations are not caused through aberrant growth or fasciculation behaviours of the pioneer neurons, but rather due to the misguidance of neurons growing at subsequent stages $[249,250]$.

The expression of these various neuronal receptors, adhesion molecules and their associated molecules involved in the neuronal response to environmental cues must be precisely regulated by pioneer neuron-intrinsic gene regulatory programmes. One candidate regulator is the neuronal transcription factor Longitudinals lacking (Lola). In the absence of Lola, longitudinal glia cells form normally, but pCC, vMP2 and MP1 growth cones stall dramatically and connectives fail to form $[23,251]$. Lola encodes a variety of isoforms that are expressed within subsets of neurons and these are likely to regulate the expression of many guidance molecules [252].

As discussed above, all these genetic pathways implicated in longitudinal fascicle formation eventually have to act on the cytoskeletal machinery of the growing neurons (Table 1 and Figure 3). In agreement with this assumption, genetic manipulations of various cytoskeletal regulators cause severe disturbances of the longitudinal tracts, as was demonstrated for Chickadee/Profilin, Abelson, members of the the Arp $2 / 3$ or SCAR/WAVE complexes, Futsch/ MAP-1B, Rho-family GTPases, such as Cdc42, combinations of Rac1, Rac2 and Mtl, or the Rac activator Trio (Figure 4 , xxxvi to xl) $[95,101,132,134,163]$. In conclusion, a clear temporal pattern of the cellular events and requirements in longitudinal pathway formation has been described at high resolution. A good number of genes, comprising adhesion, signalling or cytoskeletal regulatory factors, have been demonstrated to mediate these precise events. These reveal a significant role for interactions 
mediated by cell adhesive molecules to direct the neuronal fasciculation decisions necessary during the formation of longitudinal fascicles. These decisions are regulated by additional contact mediated signals and effected by the activation of cytoskeletal regulators.

\section{Mediolateral patterning of longitudinal fascicles}

Individual longitudinally projecting axons are positioned at particular locations within the connectives. This is mediated both by selective fasciculation behaviour and the use of protein gradients that establish positional information within the connectives to dictate where individual axons project. As explained above, longitudinal pioneer axons are initially grouped into one fascicle, but they subsequently separate into distinct fascicles in characteristic dorso-ventral and medio-lateral positions (Figure 5b) $[219,223]$. This may suggest a gradual increase in distinct positional values in the neuropile of the ventral nerve cord. In agreement with this hypothesis, the expression of the three paralogous Roundabout receptors (Robo, Robo3, Leak/Robo2) is largely overlapping at early stages of axonal growth. However, at later stages, these three receptors take on clearly distinguishable expression domains, that is, Leak/Robo2 becomes restricted to the lateral area, Robo3 spans from lateral to medial, and Robo covers the whole width of the neuropile (Figure 4, ii to iv) $[253,254]$. This provides a combinatorial code based on the number of these three Robo receptor types expressed by each particular axon, thus dictating their spatial arrangements within the connectives (Figure 5e). Experimental changes of the Robo receptor composition/dosage expressed by single neurons are sufficient to shift the position of their projections in the medio-lateral plane (Figure 4, xxix) [205,254-256]. During normal development, the state of Robo receptor expression of individual neurons appears to be determined by their cell-autonomous programmes. Thus, the expression or non-expression of the fate-determining transcription factor Atonal in chordotonal versus multidendritic sensory neurons differentially regulates their distinct medio-lateral fasciculation behaviours by instructing the expression state of the Robo3 receptor in a cell type-specific manner [255]. Similarly, the Lola transcription factor has a role to regulate the expression of Robo within central neurons [257].

The ligand to all three Robo receptors is the secreted factor Slit, which is released from glia cells in the midline of the ventral nerve cord where it is present at its maximal concentration (Figure 5e) [258]. It is also present, although at much lower levels, within the connectives, and this localisation is partly mediated by the heparan sulfate proteoglycan Syndecan (Figure 4, vi) [259]. Axons expressing a higher dosage or greater number of Robo receptor types are more sensitive to the Slit repellent and are positioned further from the midline (Figure 5e) [253,254]. In addi- tion, Robo function inactivates N-Cadherin-mediated adhesion [260]. Thus, higher Robo activity weakens the adhesive interactions driving fasciculation. This might allow growth cones with high Robo expression to progress further laterally and aid in regulating their mediolateral positioning. Consistent with this hypothesis, N-cadherin mutant embryos display aberrations of longitudinal fascicle patterns (Figure 4, xxxiv) and, at the identified cell level (apterous-expressing neurons), growth cones alter their medio-lateral pathfinding and longitudinal fasciculation behaviour in stereotypical ways (Figure 4, xxxi) [226]. It remains to be seen whether additional adhesion molecules are regulated similarly through Robo-dependent pathways.

Interestingly, axons shifted in the medio-lateral plane through targeted manipulations of their Robo genes do not project randomly but seem to partition in an organised way with a different group of axons, as suggested by their fasciculated appearance (Figure 4, xxix) $[205,254,255]$. A potential molecular explanation for this phenomenon is that the types and patterns of adhesion molecules is repeated within different mediolateral positions, allowing shifted axons to find an appropriate fascicle even in an inappropriate Robo zone.

In conclusion, both short-range interactions as well as long range organiser activity contribute to the spatial arrangement of longitudinal fascicles along the medio-lateral axis of connectives.

\section{Growth cone guidance at the Drosophila CNS midline}

The majority of axons cross the midline within either of two commissures per segment, called anterior and posterior commissures (Figures $1 \mathrm{~b}, 4 \mathrm{c}, \mathrm{d}$ and $5 \mathrm{i}$ ). The formation of these commissures begins at embryonic stage 12 and involves dynamic but reproducible interactions between pioneering growth cones, neuronal cell bodies and migrating glia cells [28], and a dynamic up- and downregulation of cell adhesion molecules, such as Fasciclin 1, during the period of axonal invasion of these commissures [8,261]. Each neuron makes a stereotypic choice as to whether to cross the midline and, for those that cross, whether to grow through the anterior or posterior commissure (Figure 5c,d). Within each commissure axons are arranged in fascicles, as illustrated by the expression pattern of molecules such as the adhesion molecule Connectin, which is restricted to specific sub-fascicles within commissures [230,231].

The Wnt5/Derailed signalling pathway (Figure 5f) plays an important role to regulate growth cone choice of anterior versus posterior commissure. Axons of the anterior commissure express the atypical receptor tyrosine kinase Derailed, which mediates their repulsion from the poste- 
rior commissure (Figure 4, xix) [208,262]. A ligand of Derailed that has been shown to mediate this commissure-specific repulsion is Wnt5, which is enriched in the area of the posterior commissure (Figure 4, xx) $[248,263]$. Absence of Derailed or Wnt 5 causes random misrouting of axons from the anterior towards the posterior commissure (Figure 4, xviii), whereas Derailed gain-of-function repels axons from the posterior commissure (Figure 4, xxii and xxvi) [208,248,263]. Obvious candidate factors organising the intrasegmental distribution of guidance cues along the antero-posterior axis are the segment polarity genes. Consistent with this assumption, embryos mutant for the segment polarity gene gooseberry have a severely reduced posterior commissure (Figure 4, xvii) $[23,264]$.

With respect to the axonal choice of whether to cross the midline or stay ipsilateral, two major regulatory pathways, the Netrin/Frazzled and Slit/Robo systems, have been identified. Cells at the midline of the ventral nerve cord express the secreted factors Netrin A and B, in the absence of which commissure formation is clearly reduced (Figure 4 , vii and xv) $[265,266]$. Although the Netrin molecules can influence the growth of axons some distance from the midline, this does not appear to be necessary for midline crossing in Drosophila, as membrane tethered versions of Netrin that necessarily act over a short-range are sufficient to attract axons across the midline [267]. In contrast, longrange signalling activity of Netrin is necessary for commissural axons to traverse the floor plate of the vertebrate spinal cord [268]. Netrin A and B act as attractive ligands to CNS axons expressing the Frazzled receptor to bring them across the midline (Figure 4, viii and xvi) [225]. However, not all neurons are attracted by Netrins, and neurons expressing the alternative receptor Unc5 are repelled by them (Figure 4, xxx) [212]. First insights are being gained into the spatial regulation of Frazzled expression. Thus, in neurons of the posterior commissure, Frazzled (together with Trio and Enabled) is directly upregulated by the segmentation gene Engrailed [269].

Another major factor guiding axons at the CNS midline and opposing the effects of Netrins is the secreted repellent factor Slit, which is also expressed by the glia cells at the midline of the ventral nerve cord (Figure 4, vi) $[258,270]$. In the absence of slit function, all axons of the ventral nerve cord collapse towards the midline (Figure 4, xiv) [23]. Slit activity to control midline crossing is mediated by the two immunoglobulin domain containing receptors, Robo and Leak/Robo2 (see 'Mediolateral patterning of longitudinal fascicles' above). Absence of these two proteins phenocopies the slit mutant phenotype (Figure $4, x i)[205,271,272]$. Thus, Slit is required to prevent axons from inappropriately reaching the midline; it acts to maintain all ipsilateral growth cones away from the mid- line, and also ensures that contralateral growth cones are prevented from re-crossing the midline. To avoid a gridlock of advancing growth cones at the midline, the opposing Slit/Robo and Netrin/Frazzled signalling pathways are precisely regulated via a number of mechanisms, which may involve cross-pathway regulation of their antagonising activities [273,274]. Also, the heterotrimeric G-protein AcGq3 has been suggested to assist in setting the balance of attractive versus repulsive cues in growth cones [275]. Alternatively, direct interactions between both signalling pathways may occur, as demonstrated in Xenopus where Robo receptors are capable of binding and inhibiting the Netrin receptor DCC [276]. The most crucial regulator of Robo activity during midline crossing in Drosophila is the short transmembrane protein Commissureless (Comm) (Figure $4, \mathrm{v}$ and xiii) [23,277]. Comm acts in commissural axons to traffic Robo away from the growth cone surface before and during crossing of the midline (Figure 5e). Subsequently, growth cones are prevented from growing back across the midline by down-regulation of Comm activity within distal regions of commissural axons following midline crossing $[207,278]$. This mechanism aids likewise in steering contralateral growth cones towards the correct medio-lateral position in the connective (Figure 5e; see 'Mediolateral patterning of longitudinal fascicles' above). The Comm-dependent sorting of Robo away from the plasma membrane has been shown to involve Nedd4 ubiquitin ligase activity [279], although details of this regulation have recently been questioned [280]. Interestingly, no Comm homologue has been found so far in mammals. Instead, midline crossing seems to be regulated by cis-inhibition of Robo1 activity through another Slit ligand, Robo3/Rig-1 [281]. However, it has recently been identified that a Rab guanine nucleotide dissociation factor is required in chick for Robo1 surface expression (E Stoeckli, personal communication), suggesting that activity of vertebrate Robo may, in part, be regulated via intracellular trafficking as in Drosophila. Furthermore, interactions between Robo receptors in Drosophila may influence each others activity (A Myat, personal communication), suggesting further parallels to the vertebrate system.

In vivo observations in normal and mutant Drosophila embryos have revealed that growth cones of the ipsilateral motorneuron RP2 form longer and more persistent filopodia in robo mutant animals, and that filopodia reaching across the midline have the unusual tendency to persist and develop into contralateral branches [84]. This clearly suggests that Robo influences the cytoskeletal machinery of these growth cones. In agreement with this notion, robo interacts genetically with mutations of the actin-plasmamembrane linker molecules beta-Spectrin/Karrussell in the context of midline crossing $[282,283]$ and Robo activity increases activity of the actin regulator, Rac [284]. 
Furthermore, it was shown that both Enabled and Abelson can bind and genetically interact with Robo, thereby providing a link from Robo to the actin cytoskeleton (Figure 3e) $[103,285-287]$. This link is further strengthened by the demonstration that Abelson, in the context of midline crossing, interacts genetically with the actin momomerbinding molecule Capulet and the microtubule plus endbinding molecule Chb/Orbit/MAST (Figure 3e) $[103,153]$. In addition, Abelson links genetically to the Netrin/Frazzled pathway [288]. Thus, Abelson seems to be a major factor orchestrating cytoskeletal dynamics in growth cones crossing the midline. Further components of the cytoskeletal machinery described in the first part of this review (Figure 3, Table 1) have been implicated in midline crossing. These factors include the Rho-like GTPases, Pak, Myosin light chain kinase, the actin-microtubule linkers DPod-1 and Short stop, RhoGAP93B/Vilse, and the RhoGEFs Sos (Son of sevenless), Trio and GEF64C (Figures $3 e$ and 5, xxxvi to xxxviii) $[119,132,134,138,143,144,169,284,288-291]$. A further 'housekeeping' factor with clear involvement at the midline is the $\mathrm{Ca}^{2+}$-binding molecule Calmodulin [289].

Apart from the three ligand receptor systems discussed above, a number of other genes have been implicated in the process of midline crossing and need to be incorporated into any model that seeks to explain how midline crossing is regulated. Thus, Amalgam, a secreted protein with three immunoglobulin domains, and its binding partner Neurotactin, a transmembrane protein with a catalytically inactive cholinesterase domain, interact with Abelson in the context of midline crossing [242]. Another molecule interacting with Abelson in midline crossing is Fasciclin 1, a lipid-linked cell-surface glycoprotein that can act as a homophilic adhesion molecule [261]. Syndecan, a transmembrane heparan sulfate proteo-glycan (HSPG) is expressed on longitudinal and commissural axons, genetically interacts with and physically binds to both Slit and Robo, and promotes their signalling $[259,292]$. Its function at the midline is partially redundant with the GPI-anchored HSPG Dally-like [259]. Furthermore, Syndecan can bind the receptor tyrosine phosphatase (RPTP) DLAR, present on many axons in the embryonic CNS [293]. Besides DLAR, another three RPTPs are expressed in the Drosophila CNS, DPTP69D, DPTP99A, and DPTP10D $[250,294]$. Of these, DPTP10D and DPTP69D seem to promote Slit/Robo function, and combined loss of both causes a robo-like midline-crossing phenotype [250]. Robo signalling is also regulated by Kuzbanian, a member of the ADAM family of metalloproteases, which may be involved in proteolytic activation of the Slit/Roundabout receptor complex [272], while Slit secretion is regulated by Schizo, an ARF6 GEF [295]. The translational inhibitor Krasavietz ( $\mathrm{Kra}$ ) is required for normal midline crossing and $k r a$ mutations interact geneti- cally with short stop, slit and robo [291]. Also, integrins and their ligands Tiggrin and Laminin A show genetic interaction with Slit in midline crossing [296]. Finally, severe midline crossing defects occur in embryos double-mutant for the genes kekkon and neurotactin, both of which encode adhesion factors [241]. Whether this phenotype also relates to the Slit/Robo function has not yet been addressed.

Taken together, an ever increasing network of factors has been discovered to play an active role in midline crossing in Drosophila, and there is hardly a cellular system of axonal growth for which there is more molecular and genetic information available. Axons must make a decision whether to cross the midline and, those that do cross, must select a commissure, and be shepherded towards, across and then away from the midline. This clearly requires a significant amount of cellular processing for which the principal mechanisms are quite well understood (Figure $5 \mathrm{e}, \mathrm{f}$ ), and work has begun to tie together the various modulatory factors into clear regulatory pathways (Figure 3e). The major ligands Wnt5, Netrin, and Slit mediate the choice of commissure, and growth towards and growth away from the midline. The effectiveness of the different ligands has to be modulated to ensure the growth cones make their appropriate responses. For example, the secretion of Slit is regulated by Schizo, while the action of Slit is modulated by proteoglycans and the promotion of attraction or repulsion at the midline carefully regulated by the integration of multiple downstream effectors to ensure a coherent response (Figure 3e). The activity of the major receptors Robo and Frazzled are finely regulated both transcriptionally and post-transcriptionally in crossing and non-crossing axons to ensure they migrate along their appropriate pathways. Finally, the fidelity of these pathway choices is also influenced by cell adhesive interactions and potentially the activity of receptor phosphatases. A good number of the major players involved in midline crossing are conserved across the animal kingdom $[297,298]$, and this work has already had implications for medical research, as demonstrated by the association of human gaze palsy with progressive scoliosis (HGPPS) with mutations of the robo3 receptor gene [299].

\section{Conclusions and perspectives}

A number of well characterised and experimentally amenable cellular systems for the study of axonal growth in situ have been established in Drosophila. Combined with the genetic tractability of the fruit fly, these cellular systems have helped to uncover an impressive palette of molecular mechanisms underlying axonal growth, many of which can be translated into axonal growth processes in higher organisms. However, a number of challenges and open questions still remain to be addressed in the Drosophila system. 
First, more analyses need to be carried forward to the identified cell level using cell-specific markers (Figure 4, $\mathrm{xv}$ versus xxiii, or xxxi versus xxxiv), thus enabling molecular functions to be assigned more precisely to their immediate cellular role. Also, such analyses would provide better means to study the integration of different molecular pathways or activities, especially when capitalising on the same sets of cells as read-outs. Second, of particular interest in current research on neuronal growth are the mechanisms linking the signalling machinery of axon guidance to the factors regulating the growth cone's cytoskeleton and, thus, its morphogenetic dynamics. To carry out such research in Drosophila, work at the subcellular level of growth cones will have to be intensified, and the feasibility of such work has clearly been demonstrated (see 'Growth cones in Drosophila' above). Third, with respect to pathfinding mechanisms in the ventral nerve cord, virtually nothing is known about growth regulation in the dorso-ventral axis, which may be due to the fact that the read-outs used in most genetic screens would not easily reveal growth aberrations within the vertical axis. Improved cellular systems and closer attention to this aspect of axon growth should ensure that mechanisms will be found in due course [255]. Future searches for such factors could be facilitated by the fact that whole neuronal subgroups show stereotypic dorso-ventral growth behaviours: most sensory neurons (except for vbd- and dbdneurons) innervate the ventral neuropile, whereas all motor axons grow towards dorsal neuropile areas, where they form dendrites (Figure 2a) $[19,236,300]$. Fourth, redundancy of mechanisms is an obvious issue, and more double- or triple-mutant constellations, especially of adhesive and signalling factors, will have to be tested to appreciate their real requirements during nervous system development $[241,301]$. Fifth, we have still few insights into the transcriptional control over the pathfinding machinery in individual neurons, although a number of transcription factors related to growth behaviour have been described [49,251,252,255,302-304]. Improved means to identify the genes regulated by these factors, such as DamID or ChIP-on-chip technology [302,305], will advance our knowledge at this level of growth control. Finally, a whole palette of mutations with exciting phenotypes has been obtained in various genetic screens (see 'Models for axonal growth in Drosophila' above), and many of them are still awaiting their detailed analysis. Consequent work in these directions will ensure that Drosophila will continue to contribute essential new insights to the field of neuronal growth.

\section{Competing interests}

The author(s) declare that they have no competing interests.

\section{Authors' contributions}

The first draft of this review was written by NSS together with AP, which was then refined, corrected and complemented by GT and PW. All figures were composed by AP with image contributions by NSS (Figures $3 \mathrm{a}$, b and $4 \mathrm{a}$ ) and design of the genetic interaction scheme (Figure $3 \mathrm{e}$ ) by GT.

\section{Acknowledgements}

We are grateful to Christoph Ballestrem, Theresia Stradal and Klemens Rottner for constructive criticism, to Esther Stoeckli, Richard Tuxworth and Anna Myat for personal communication of results, and to Janina Seibert, Christoph Rickert and Gerd Technau for contributing images to Figure 5. The work of AP and NS.-S on growth cones is supported by a grant from the Wellcome Trust (077748/Z/05/Z). Work in the laboratory of GT is funded by the Wellcome Trust (075264/B/04/Z) and the MRC (G040I440 and G050026I), and PW is supported by the Australian Research Council (DP0558835) and National Health and Medical Research Council (350426).

\section{References}

I. Ramón y Cajal S: Histology of the Nervous System of Man and Vertebrates (English translation by Swanson N, Swanson LW from 1995) New York Oxford: Oxford University Press; 1909:1911.

2. Tessier-Lavigne M, Goodman CS: The molecular biology of axon guidance. Science 1996, 274: I I23-I I33.

3. Araujo SJ, Tear G: Axon guidance mechanisms and molecules: lessons from invertebrates. Nat Rev Neurosci 2003, 4:910-922.

4. Bate CM: Pioneer neurones in an insect embryo. Nature 1976, 260:54-56.

5. Harrison RG: The outgrowth of the nerve fiber as a mode of protoplasmic movement. J Exp Zool 1910, 9:787-846.

6. Goodman CS, Bastiani MJ, Doe CQ, du Lac S, Helfand SL, Kuwada JY, Thomas JB: Cell recognition during neuronal development. Science 1984, 225: I27I-1279.

7. Raper JA, Bastiani M, Goodman CS: Pathfinding by neuronal growth cones in grasshopper embryos. II. Selective fasciculation onto specific axonal pathways. J Neurosci 1983, 3:3I-4I.

8. Goodman CS, Doe CQ: Embryonic development of the Drosophila central nervous system. In The Development of Drosophila Volume I. Edited by: Bate M, Martínez-Arias A. Cold Spring Harbor, New York: Cold Spring Harbor Laboratory Press; 1993: I I31- 1206.

9. Sánchez-Soriano N, Prokop A: The influence of pioneer neurons on a growing motor nerve in Drosophila requires the neural cell adhesion molecule homolog Fasciclinll. J Neurosci 2005, 25:78-87.

10. Thomas JB, Bastiani MJ, Bate M, Goodman CS: From grasshopper to Drosophila: a common plan for neural development. Nature 1984, 31 0:203-207.

II. Fujita SC, Zipursky SL, Benzer S, Ferrús A, Shotwell SL: Monoclonal antibodies against the Drosophila nervous system. Proc Natl Acad Sci USA 1982, 79:7929-7933.

12. Zipursky SL, Venkatesh TR, Teplow DB, Benzer S: Neuronal development in the Drosophila retina: monoclonal antibodies as molecular probes. Cell 1984, 36:15-26.

13. St Johnston D: The art and design of genetic screens: Drosophila melanogaster. Nat Rev Genet 2002, 3:176-188.

14. Drysdale RA, Crosby MA, Gelbart W, Campbell K, Emmert D, Matthews B, Russo S, Schroeder A, Smutniak F, Zhang P, et al.: FlyBase: genes and gene models. Nucleic Acids Res 2005:D390-395.

15. Campos-Ortega JA, Hartenstein V: The embryonic development of Drosophila melanogaster. Berlin: Springer Verlag; 1997.

16. Ashburner M, Golic KG, Hawley RS: Drosophila: a Laboratory Handbook 2nd edition. Cold Spring Harbor, New York: Cold Spring Harbor Laboratory Press; 2005.

17. Matthews KA, Kaufman TC, Gelbart WM: Research resources for Drosophila: the expanding universe. Nat Rev Genet 2005, 6:179-193.

18. Bate M, Martínez-Arias A: The Development of Drosophila melanogaster Volume I and 2. Cold Spring Harbor, New York: Cold Spring Harbor Laboratory Press; 1993. 
19. Sánchez-Soriano N, Löhr R, Bottenberg W, Haessler U, Kerassoviti A, Knust E, Fiala A, Prokop A: Are dendrites in Drosophila homologous to vertebrate dendrites? Dev Biol 2005, 288: $|26-| 38$.

20. Teillet MA, Kalcheim C, Le Douarin NM: Formation of the dorsal root ganglia in the avian embryo: segmental origin and migratory behavior of neural crest progenitor cells. Dev Biol 1987, I 20:329-347.

21. Garcia-Alonso L, Fetter RD, Goodman CS: Genetic analysis of Laminin A in Drosophila: extracellular matrix containing laminin $\mathbf{A}$ is required for ocellar axon pathfinding. Development 1996, I 22:261|-2621.

22. Truman JW, Taylor BJ, Awad TA: Formation of the adult nervous system. In The Development of Drosophila melanogaster Volume 2. Edited by: Bate M, Martínez Arias A. Cold Spring Harbor, New York: Cold Spring Harbor Laboratory Press; 1993: 1245-1275.

23. Seeger M, Tear G, Ferres MD, Goodman CS: Mutations affecting growth cone guidance in Drosophila: genes necessary for guidance toward or away from the midline. Neuron 1993, 10:409-426.

24. VanVactor DV, Sink H, Fambrough D, Tsoo R, Goodman CS: Genes that control neuromuscular specificity in Drosophila. Cell 1993, 73:1137-1153.

25. Kolodziej PA, Jan LY, Jan YN: Mutations that affect the length, fasciculation, or ventral orientation of specific sensory axons in the Drosophila embryo. Neuron 1995, 15:273-286.

26. Schmucker D, Jäckle H, Gaul U: Genetic analysis of the larval optic nerve projection in Drosophila. Development 1997, 1 24:937-948.

27. Bier E, Vässin H, Shepherd S, Lee K, McCall K, Barbel S, Ackerman L, Carretto R, Uemura T, Grell E, et al.: Searching for pattern and mutation in the Drosophila genome with a P-lac $Z$ vector. Genes Dev 1989, 3:1273-1287.

28. Klämbt C, Jacobs JR, Goodman CS: The midline of the Drosophila central nervous system: a model for the genetic analysis of cell fate, cell migration, and growth cone guidance. Cell I99I, 64:80I-8I5.

29. Hummel T, Schimmelpfeng K, Klambt C: Commissure formation in the embryonic CNS of Drosophila. I. Identification of the required gene functions. Dev Biol 1999, 209:38I-398.

30. Salzberg A, D'Evelyn D, Schulze KL, Lee JK, Strumpf D, Tsai L, Bellen $\mathrm{HJ}$ : Mutations affecting the pattern of the PNS in Drosophila reveal novel aspects of neuronal development. Neuron 1994, 13:269-287.

31. Prokopenko SN, He Y, Lu Y, Bellen HJ: Mutations affecting the development of the peripheral nervous system in Drosophila: a molecular screen for novel proteins. Genetics 2000, 156:169I-I7I5.

32. McGovern VL, Pacak CA, Sewell ST, Turski ML, Seeger MA: A targeted gain of function screen in the embryonic CNS of Drosophila. Mech Dev 2003, 120: | 193-1207.

33. Thomas JB, Wyman RJ: Mutations altering synaptic connectivity between identified neurons in Drosophila. I Neurosci 1984, 4:530-538.

34. Heisenberg M, Böhl K: Isolation of anatomical brain mutants of Drosophila by histological means. Z Naturforsch 1979, 34: $143-147$

35. Newsome TP, Asling B, Dickson BJ: Analysis of Drosophila photoreceptor axon guidance in eye-specific mosaics. Development 2000, I 27:851-860.

36. Martin KA, Poeck B, Roth H, Ebens AJ, Ballard LC, Zipursky SL: Mutations disrupting neuronal connectivity in the Drosophila visual system. Neuron 1995, 14:229-240.

37. Lee T, Luo L: Mosaic analysis with a repressible neurotechnique cell marker for studies of gene function in neuronal morphogenesis. Neuron 1999, 22:45|-46I.

38. Reuter JE, Nardine TM, Penton A, Billuart P, Scott EK, Usui T, Uemura T, Luo L: A mosaic genetic screen for genes necessary for Drosophila mushroom body neuronal morphogenesis. Development 2003, I30:1203-1213.

39. Jefferis GS, Hummel T: Wiring specificity in the olfactory system. Semin Cell Dev Biol 2006, 1 7:50-65.

40. Lee CH, Herman T, Clandinin TR, Lee R, Zipursky SL: N-cadherin regulates target specificity in the Drosophila visual system. Neuron 200I, 30:437-450.
4I. Forni JJ, Romani S, Doherty P, Tear G: Neuroglian and FasciclinII can promote neurite outgrowth via the FGF receptor Heartless. Mol Cell Neurosci 2004, 26:282-29I.

42. Takagi Y, Nomizu M, Gullberg D, MacKrell AJ, Keene DR, Yamada Y, Fessler $\mathrm{JH}$ : Conserved neuron promoting activity in Drosophila and vertebrate laminin alphal. J Biol Chem 1996, 27I:I8074-I808I.

43. Takagi Y, Ui-Teib K, Miyakec T, Hirohashia S: Laminin-dependent integrin clustering with tyrosinephosphorylated molecules in a Drosophila neuronal cell line. Neurosci Letters 1998, 244:149-152.

44. Küppers-Munther B, Letzkus J, Lüer K, Technau G, Schmidt $H$, Prokop A: A new culturing strategy optimises Drosophila primary cell cultures for structural and functional analyses. Dev Biol 2004, 269:459-478.

45. Kim YT, Wu CF: Reversible blockage of neurite development and growth cone formation in neuronal cultures of a temperature-sensitive mutant of Drosophila. J Neurosci 1987, 7:3245-3255.

46. Masur SK, Kim YT, Wu CF: Reversible inhibition of endocytosis in cultured neurons from the Drosophila temperature-sensitive mutant shibiretsI. J Neurogenet 1990, 6:191-206.

47. Yao W-D, Rusch J, Poo M-m, Wu C-F: Spontaneous acetylcholine secretion from developing growth cones of Drosophila central neurons in culture: effects of cAMP-pathway mutations. J Neurosci 2000, 20:2626-2637.

48. Yang $\mathrm{H}$, Kunes $\mathrm{S}$ : Nonvesicular release of acetylcholine is required for axon targeting in the Drosophila visual system. Proc Natl Acad Sci USA 2004, I01:152 13-15218.

49. Landgraf $M$, Thor S: Development of Drosophila motoneurons: specification and morphology. Semin Cell Dev Biol 2006, 17:3-II.

50. Williams DW, Truman JW: Cellular mechanisms of dendrite pruning in Drosophila: insights from in vivo time-lapse of remodeling dendritic arborizing sensory neurons. Development 2005, 132:3631-3642

5I. Gao FB, Bogert BA: Genetic control of dendritic morphogenesis in Drosophila. Trends Neurosci 2003, 26:262-268.

52. Budnik V, Ruiz-Cañada C: The Fly Neuromuscular Junction: Structure and Function 2nd edition. San Diego: Elsevier Academic Press; 2006.

53. Ramón y Cajal S: À quelle époque apparaissent les expansions des cellules nerveuses de la moëlle épinière du poulet. Anatomischer Anzeiger 1890, 21-22:609-639.

54. Harrison RG: Observations on the living developing nerve fiber. Anat Rec 1907, I: I 16-I I8.

55. Dent EW, Gertler FB: Cytoskeletal dynamics and transport in growth cone motility and axon guidance. Neuron 2003, 40:209-227.

56. Goldberg JL: How does an axon grow? Genes Dev 2003, I7:94I-958

57. Shi S-H, Jan LY, Jan Y-N: Hippocampal neuronal polarity specified by spatially localized $\mathrm{mPar} / \mathrm{mPar6}$ and PI 3-Kinase activity. Cell 2003, I I 2:63-75.

58. Suter DM, Forscher P: Substrate-cytoskeletal coupling as a mechanism for the regulation of growth cone motility and guidance. J Neurobiol 2000, 44:97-II3.

59. Kalil K, Dent EW: Touch and go: guidance cues signal to the growth cone cytoskeleton. Curr Opin Neurobiol 2005, I 5:52 I-526.

60. Zhou FQ, Cohan CS: How actin filaments and microtubules steer growth cones to their targets. J Neurobiol 2004, 58:84-9I.

61. Renaudin A, Lehmann M, Girault J, McKerracher L: Organization of point contacts in neuronal growth cones. J Neurosci Res 1999, 55:458-471.

62. Robles E, Gomez TM: Focal adhesion kinase signaling at sites of integrin-mediated adhesion controls axon pathfinding. Nat Neurosci 2006, 9: I 274-1283.

63. Suter DM, Schaefer AW, Forscher P: Microtubule dynamics are necessary for Src family kinase-dependent growth cone steering. Curr Biol 2004, 14:1 194-II 99.

64. Carlier MF: Actin: protein structure and filament dynamics. J Biol Chem 1991, 266: I-4.

65. Disanza A, Steffen A, Hertzog M, Frittoli E, Rottner K, Scita G: Actin polymerization machinery: the finish line of signaling networks, the starting point of cellular movement. Cell Mol Life Sci 2005, 62:955-970.

66. Gungabissoon RA, Bamburg JR: Regulation of growth cone actin dynamics by ADF/cofilin. J Histochem Cytochem 2003, 5 I :4 I I-420. 
67. Vignjevic D, Yarar D, Welch MD, Peloquin J, Svitkina T, Borisy GG: Formation of filopodia-like bundles in vitro from a dendritic network. J Cell Biol 2003, I 60:951-962.

68. Svitkina TM, Bulanova EA, Chaga OY, Vignjevic DM, Kojima S, Vasiliev JM, Borisy GG: Mechanism of filopodia initiation by reorganization of a dendritic network. / Cell Biol 2003, I 60:409-42I.

69. Faix J, Rottner K: The making of filopodia. Curr Opin Cell Biol 2006, I 8: 18-25.

70. Yamada KM, Wessells NK: Cytochalasin B: effects on membrane ruffling, growth cone and microspike activity, and microfilament structure not due to altered glucose transport. Dev Biol 1973, 3 I:4I 3-420.

7I. Wu CF, Sakai K, Saito M, Hotta Y: Giant Drosophila neurons differentiated from cytokinesis-arrested embryonic neuroblasts. J Neurobiol 1990, 2 I:499-507.

72. Kaufmann N, Wills ZP, Van Vactor D: Drosophila Racl controls motor axon guidance. Development |998, | 25:453-46 I.

73. Bray D, Thomas C, Shaw G: Growth cone formation in cultures of sensory neurons. Proc Natl Acad Sci USA 1978, 75:5226-5229.

74. McCaig CD: Nerve growth in the absence of growth cone filopodia and the effects of a small applied electric field. J Cell Sci 1989, 93(Pt 4):7|5-72|.

75. Wang HW, Nogales E: Nucleotide-dependent bending flexibility of tubulin regulates microtubule assembly. Nature 2005 435:911-915.

76. Kerssemakers JW, Laura Munteanu E, Laan L, Noetzel TL, Janson ME Dogterom M: Assembly dynamics of microtubules at molecular resolution. Nature 2006, 442:709-712.

77. Mahadevan L, Mitchison T]: Cell biology: powerful curves. Nature 2005, 435:895-897.

78. Wu C-F, Suzuki N, Poo M: Dissociated neurons from normal and mutant Drosophila larval central nervous system in cell culture. J Neurosci 1983, 3:1888-1899.

79. Kim YT, Wu CF: Distinctions in growth cone morphology and motility between monopolar and multipolar neurons in Drosophila CNS cultures. J Neurobiol I991, 22:263-275.

80. Kim YT, Wu CF: Reduced growth cone motility in cultured neurons from Drosophila memory mutants with a defective cAMP cascade. J Neurosci 1996, 16:5593-5602.

81. Sink H, Whitington PM: Pathfinding in the central nervous system and periphery by identified embryonic Drosophila motor axons. Development 1991, I | 2:307-316.

82. Jacobs JR, Goodman CS: Embryonic development of axon pathways in the Drosophila CNS. II. Behavior of pioneer growth cones. I Neurosci 1989, 9:24I2-2422.

83. Murray MJ, Merritt $D$, Brand $A H$, Whitington $P M$ : In vivo dynamics of axon pathfinding in the Drosophila CNS: A time-lapse study of an identified motorneuron. I Neurobiol 1998 37:607-621

84. Murray MJ, Whitingron PM: Effects of roundabout on growth cone dynamics, filopodial length, and growth cone morphology at the midline and throughout the neuropile. I Neurosci 1999, 19:7901-7912

85. Kim MD, Kolodziej P, Chiba A: Growth cone pathfinding and filopodial dynamics are mediated separately by Cdc42 activation. J Neurosci 2002, 22: I794-1806.

86. Kim MD, Kamiyama D, Kolodziej P, Hing H, Chiba A: Isolation of Rho GTPase effector pathways during axon development. Dev Biol 2003, 262:282-293.

87. Kim GJ, Shatz CJ, McConnell SK: Morphology of pioneer and follower growth cones in the developing cerebral cortex. J Neurobiol 1991, 22:629-642.

88. Bak M, Fraser SE: Axon fasciculation and differences in midline kinetics between pioneer and follower axons within commissural fascicles. Development 2003, 130:4999-5008.

89. Broadie KS, Bate M: Development of the embryonic neuromuscular synapse of Drosophila melanogaster. J Neurosci 1993, 13:144-166

90. Yoshihara M, Rheuben MB, Kidokoro $Y$ : Transition from growth cone to functional motor nerve terminal in Drosphila embryos. J Neurosci 1997, I 7:8408-8426.

91. Suzuki E, Rose D, Chiba A: The ultrastructural interactions of identified pre- and postsynaptic cells during synaptic target recognition in Drosophila embryos. J Neurobiol 2000, 42:448-459
92. Sink H, Whitington PM: Early ablation of target muscles modulates the arborisation pattern of an identified embryonic Drosophila motor axon. Development I99I, I I 3:701-707.

93. Kunda P, Craig G, Dominguez V, Baum B: Abi, Sral, and Kette control the stability and localization of SCAR/WAVE to regulate the formation of actin-based protrusions. Curr Biol 2003 , I3:|867-|875.

94. Hudson AM, Cooley L: A subset of dynamic actin rearrangements in Drosophila requires the Arp2/3 complex. J Cell Biol 2002, I 56:677-687.

95. Zallen JA, Cohen Y, Hudson AM, Cooley L, Wieschaus E, Schejter ED: SCAR is a primary regulator of Arp2/3-dependent morphological events in Drosophila. J Cell Biol 2002, I 56:689-70I.

96. Quinlan ME, Heuser JE, Kerkhoff E, Mullins RD: Drosophila Spire is an actin nucleation factor. Nature 2005, 433:382-388.

97. Kovar DR: Molecular details of formin-mediated actin assembly. Curr Opin Cell Biol 2006, I 8: I I-I7.

98. Tanaka H, Takasu E, Aigaki T, Kato K, Hayashi S, Nose A: Formin3 is required for assembly of the F-actin structure that mediates tracheal fusion in Drosophila. Dev Biol 2004, 274:4I 3-425.

99. Strasser GA, Rahim NA, VanderWaal KE, Gertler FB, Lanier LM: Arp 2/3 is a negative regulator of growth cone translocation. Neuron 2004, 43:81-94.

100. Gertler FB, Comer AR, Juang J-L, Ahern SM, Clark MJ, Liebl EC, Hoffmann FM: enabled, a dosage-sensitive suppressor of mutations in the Drosophila Abl tyrosine kinase, encodes an Abl substrate with SH3 domain-binding properties. Genes Dev 1995, 9:521-533.

101. Wills Z, Marr L, Zinn K, Goodman CS, Van Vactor D: Profilin and the $A b l$ tyrosine kinase are required for motor axon outgrowth in the Drosophila embryo. Neuron 1999, 22:291-299.

102. Boquet I, Boujemaa R, Carlier MF, Preat T: Ciboulot regulates actin assembly during Drosophila brain metamorphosis. Cell 2000, 102:797-808.

103. Wills Z, Emerson M, Rusch J, Bikoff J, Baum B, Perrimon N, Van Vactor D: A Drosophila homolog of cyclase-associated proteins collaborates with the Abl tyrosine kinase to control midline axon pathfinding. Neuron 2002, 36:61 I-622.

104. Wahlström G, Vartiainen M, Yamamoto L, Mattila PK, Lappalainen P, Heino TI: Twinfilin is required for actin-dependent developmental processes in Drosophila. J Cell Biol 200I, I 55:787-796.

105. Kim YS, Furman S, Sink H, VanBerkum MF: Calmodulin and profilin coregulate axon outgrowth in Drosophila. J Neurobiol 200 I, 47:26-38.

106. Berke B, Wu CF: Regional calcium regulation within cultured Drosophila neurons: effects of altered cAMP metabolism by the learning mutations dunce and rutabaga. J Neurosci 2002 , 22:4437-4447.

107. Henley J, Poo MM: Guiding neuronal growth cones using $\mathbf{C a}^{2+}$ signals. Trends Cell Biol 2004, 14:320-330.

108. Berke BA, Lee J, Peng IF, Wu C-F: Sub-cellular $\mathrm{Ca}^{2+}$ dynamics affected by voltage- and $\mathrm{Ca}^{2+}$-gated $\mathrm{K}^{+}$channels: Regulation of the soma-growth cone disparity and the quiescent state in Drosophila neurons. Neuroscience 2006, I42:629-644.

109. Janody F, Treisman JE: Actin capping protein \{alpha\} maintains vestigial-expressing cells within the Drosophila wing disc epithelium. Development 2006, I33:3349-3357.

I I0. Ono S: Mechanism of depolymerization and severing of actin filaments and its significance in cytoskeletal dynamics. Int Rev Cytol 2007, 258: I-82.

I I I. Ng J, Luo L: Rho GTPases regulate axon growth through convergent and divergent signaling pathways. Neuron 2004, 44:779-793.

I 12. Andrianantoandro E, Pollard TD: Mechanism of actin filament turnover by severing and nucleation at different concentrations of ADF/Cofilin. Mol Cell 2006, 24: I3-23.

I 13. Endo M, Ohashi K, Sasaki Y, Goshima Y, Niwa R, Uemura T, Mizuno $\mathrm{K}$ : Control of growth cone motility and morphology by LIM kinase and Slingshot via phosphorylation and dephosphorylation of Cofilin. I Neurosci 2003, 23:2527-2537.

114. McGough AM, Staiger CJ, Min JK, Simonetti KD: The gelsolin family of actin regulatory proteins: modular structures, versatile functions. FEBS Lett 2003, 552:75-8I

I 15. Straub KL, Stella MC, Leptin M: The gelsolin-related flightless I protein is required for actin distribution during cellularisation in Drosophila. J Cell Sci 1996, 109:263-270. 
I 16. Matova N, Mahajan-Miklos S, Mooseker MS, Cooley L: Drosophila quail, a villin-related protein, bundles actin filaments in apoptotic nurse cells. Development 1999, I 26:5645-5657.

I I7. Turney SG, Bridgman PC: Laminin stimulates and guides axonal outgrowth via growth cone myosin II activity. Nat Neurosci 2005, 8:717-719.

I 18. Suter DM, Forscher P: Transmission of growth cone traction force through apCAM-cytoskeletal linkages is regulated by Src family tyrosine kinase activity. I Cell Biol 200I, I 55:427-438.

119. Kim YS, Fritz JL, Seneviratne AK, VanBerkum MF: Constitutively active myosin light chain kinase alters axon guidance decisions in Drosophila embryos. Dev Biol 2002, 249:367-38I.

120. Lee A, Treisman JE: Excessive Myosin activity in mbs mutants causes photoreceptor movement out of the Drosophila eye disc epithelium. Mol Biol Cell 2004, I 5:3285-3295.

121. Young PE, Richman AM, Ketchum AS, Kiehart DP: Morphogenesis in Drosophila requires nonmuscle myosin heavy chain function. Genes Dev 1993, 7:29-4I.

122. Bachmann C, Fischer L, Walter U, Reinhard M: The EVH2 domain of the vasodilator-stimulated phosphoprotein mediates tetramerization, F-actin binding, and actin bundle formation. J Biol Chem 1999, 274:23549-23557.

123. Schirenbeck A, Arasada R, Bretschneider T, Stradal TE, Schleicher M Faix J: The bundling activity of vasodilator-stimulated phosphoprotein is required for filopodium formation. Proc Natl Acad Sci USA 2006, I 03:7694-7699.

124. Adams JC: Roles of fascin in cell adhesion and motility. Curr Opin Cell Biol 2004, I 6:590-596.

125. Vignjevic D, Kojima S, Aratyn Y, Danciu O, Svitkina T, Borisy GG: Role of fascin in filopodial protrusion. J Cell Biol 2006, I 74:863-875.

126. Kraft R, Escobar MM, Narro ML, Kurtis JL, Efrat A, Barnard K, Restifo LL: Phenotypes of Drosophila brain neurons in primary culture reveal a role for fascin in neurite shape and trajectory J Neurosci 2006, 26:8734-8747.

127. Brieher WM, Coughlin M, Mitchison TJ: Fascin-mediated propulsion of Listeria monocytogenes independent of frequent nucleation by the Arp2/3 complex. J Cell Biol 2004, I 65:233-242.

128. Wahlström G, Lahti VP, Pispa J, Roos C, Heino TI: Drosophila nonmuscle alpha-actinin is localized in nurse cell actin bundles and ring canals, but is not required for fertility. Mech Dev 2004, 121:1377-1391.

129. Dubnau J, Chiang AS, Grady L, Barditch J, Gossweiler S, McNeil J, Smith P, Buldoc F, Scott R, Certa U, et al.: The staufen/pumilio pathway is involved in Drosophila long-term memory. Curr Biol 2003, I 3:286-296.

130. Dickson BJ: Rho GTPases in growth cone guidance. Curr Opin Neurobiol 2001, I I:103-II0.

131. Luo L: Actin cytoskeleton regulation in neuronal morphogenesis and structural plasticity. Annu Rev Cell Dev Biol 2002 I 8:601-635.

132. Hakeda-Suzuki S, Ng J, Tzu J, Dietzl G, Sun Y, Harms M, Nardine T, Luo L, Dickson BJ: Rac function and regulation during Drosophila development. Nature 2002, 4 I 6:438-442.

133. Ng J, Nardine T, Harms M, Tzu J, Goldstein A, Sun Y, Dietzl G, Dickson BJ, Luo L: Rac GTPases control axon growth, guidance and branching. Nature 2002, 4I 6:442-447.

134. Matsuura R, Tanaka H, Go MJ: Distinct functions of Racl and Cdc42 during axon guidance and growth cone morphogenesis in Drosophila. Eur J Neurosci 2004, 19:21-31.

135. Lee T, Winter C, Marticke SS, Lee A, Luo L: Essential roles of Drosophila $R$ hoA in the regulation of neuroblast proliferation and dendritic but not axonal morphogenesis. Neuron 2000, 25:307-316.

136. Johndrow JE, Magie CR, Parkhurst SM: Rho GTPase function in flies: insights from a developmental and organismal perspective. Biochem Cell Biol 2004, 82:643-657.

137. Rubin GM, Yandell MD, Wortman JR, Gabor Miklos GL, Nelson CR, Hariharan IK, Fortini ME, Li PW, Apweiler R, Fleischmann W, et al: Comparative genomics of the eukaryotes. Science 2000 , 287:2204-2215.

138. Bashaw G], Hu H, Nobes CD, Goodman CS: A novel Dbl family RhoGEF promotes Rho-dependent axon attraction to the central nervous system midline in Drosophila and overcomes Robo repulsion. J Cell Biol 200I, I55: I I 17-II22.
139. Billuart P, Winter CG, Maresh A, Zhao X, Luo L: Regulating axon branch stability: the role of $p \mid 90$ RhoGAP in repressing a retraction signaling pathway. Cell 2001, I 07:195-207.

140. Sone M, Hoshino M, Suzuki E, Kuroda S, Kaibuchi K, Nakagoshi H, Saigo K, Nabeshima Y, Hama C: Still life, a protein in synaptic terminals of Drosophila homologous to GDP-GTP exchangers. Science 1997, 275:543-547.

14I. Newsome TP, Schmidt S, Dietzl G, Keleman K, Asling B, Debant A, Dickson $B$ J: Trio combines with dock to regulate Pak activity during photoreceptor axon pathfinding in Drosophila. Cell 2000, I 0 I :283-294

142. Bateman J, Shu H, Van Vactor D: The guanine nucleotide exchange factor trio mediates axonal development in the Drosophila embryo. Neuron 2000, 26:93-106.

143. Lundström A, Gallio M, Englund C, Steneberg P, Hemphala J, Aspenstrom P, Keleman K, Falileeva L, Dickson BJ, Samakovlis C: Vilse, a conserved Rac/Cdc42 GAP mediating Robo repulsion in tracheal cells and axons. Genes Dev 2004, I 8:2 I6I-2 I7I .

144. Hu H, Li M, Labrador JP, McEwen J, Lai EC, Goodman CS, Bashaw G]: Cross GTPase-activating protein (CrossGAP)/Vilse links the Roundabout receptor to $\mathrm{Rac}$ to regulate midline repulsion. Proc Natl Acad Sci USA 2005, I 02:4613-46I8.

145. Hing H, Xiao J, Harden N, Lim L, Zipursky SL: Pak functions downstream of Dock to regulate photoreceptor axon guidance in Drosophila. Cell 1999, 97:853-863.

146. Ruan W, Pang $P$, Rao $Y$ : The SH2/SH3 adaptor protein dock interacts with the Ste20-like kinase misshapen in controlling growth cone motility. Neuron 1999, 24:595-605.

147. Takenawa T, Suetsugu S: The WASP-WAVE protein network: connecting the membrane to the cytoskeleton. Nat Rev Mol Cell Biol 2007, 8:37-48.

148. Schenck A, Bardoni B, Langmann C, Harden N, Mandel JL, Giangrande A: CYFIP/Sra-I controls neuronal connectivity in Drosophila and links the Racl GTPase pathway to the fragile $X$ protein. Neuron 2003, 38:887-898.

149. Schenck A, Qurashi A, Carrera P, Bardoni B, Diebold C, Schejter E, Mandel JL, Giangrande A: WAVE/SCAR, a multifunctional complex coordinating different aspects of neuronal connectivity. Dev Biol 2004, 274:260-270.

150. Kornack DR, Giger RJ: Probing microtubule +TIPs: regulation of axon branching. Curr Opin Neurobiol 2005, I 5:58-66.

15I. Amos LA, Schlieper D: Microtubules and maps. Adv Protein Chem 2005, $71: 257-298$.

I52. Lantz VA, Miller KG: A class VI unconventional myosin is associated with a homologue of a microtubule-binding protein, cytoplasmic linker protein- 170 , in neurons and at the posterior pole of Drosophila embryos. J Cell Biol I998, I40:897-910.

I53. Lee H, Engel U, Rusch J, Scherrer S, Sheard K, Van Vactor D: The microtubule plus end tracking protein Orbit/MAST/CLASP acts downstream of the tyrosine kinase $\mathrm{Abl}$ in mediating axon guidance. Neuron 2004, 42:913-926.

154. Akong K, McCartney BM, Peifer M: Drosophila APC2 and APCI have overlapping roles in the larval brain despite their distinct intracellular localizations. Dev Biol 2002, 250:71-90.

I55. Elliott SL, Cullen CF, Wrobel N, Kernan MJ, Ohkura H: EB I is essential during Drosophila development and plays a crucial role in the integrity of chordotonal mechanosensory organs. Mol Biol Cell 2005, I 6:891-901.

156. Zheng Y: G protein control of microtubule assembly. Annu Rev Cell Dev Biol 2004, 20:867-894.

I57. Ruiz-Cañada C, Ashley J, Moeckel-Cole S, Drier E, Yin J, Budnik V: New synaptic bouton formation is disrupted by misregulation of microtubule stability in aPKC mutants. Neuron 2004, 42:567-580.

I58. Liu Z, Steward R, Luo L: Drosophila Lis I is required for neuroblast proliferation, dendritic elaboration and axonal transport. Nat Cell Biol 2000, 2:776-783.

159. Sapir T, Elbaum M, Reiner O: Reduction of microtubule catastrophe events by LISI, platelet-activating factor acetylhydrolase subunit. EMBO j 1997, 16:6977-6984.

160. Vallee RB, Tsai JW: The cellular roles of the lissencephaly gene LISI, and what they tell us about brain development. Genes Dev 2006, 20:1384-1393.

16I. Heidary G, Fortini ME: Identification and characterization of the Drosophila tau homolog. Mech Dev 200I, I08:I7I-I78. 
162. Goldstein LS, Gunawardena S: Flying through the Drosophila cytoskeletal genome. J Cell Biol 2000, 150:F63-68.

163. Hummel T, Krukkert K, Roos J, Davis G, Klämbt C: Drosophila Fut$\mathrm{sch} / 22 \mathrm{ClO}$ is a MAPIB-like protein required for dendritic and axonal development. Neuron 2000, 26:357-370.

164. Wills Z, Bateman J, Korey CA, Corner A, Van Vactor D: The tyrosine kinase $\mathrm{Abl}$ and its substrate enabled collaborate with the receptor phosphatase Dlar to control motor axon guidance. Neuron 1999, 22:30I-3/2.

165. Griffith LM, Pollard TD: Evidence for actin filament-microtubule interaction mediated by microtubule-associated proteins. J Cell Biol I978, 78:958-965.

166. Dehmelt L, Halpain S: The MAP2/Tau family of microtubuleassociated proteins. Genome Biol 2005, 6:204.

167. Röper K, Gregory SL, Brown NH: The 'Spectraplakins': cytoskeletal giants with characteristics of both spectrin and plakin families. J Cell Sci 2002, I I 5:4215-4225.

168. Lee S, Kolodziej PA: Short stop provides an essential link between F-actin and microtubules during axon extension. Development 2002, I 29: I 195-I 204.

169. Rothenberg ME, Rogers SL, Vale RD, Jan LY, Jan YN: Drosophila pod-I crosslinks both actin and microtubules and controls the targeting of axons. Neuron 2003, 39:779-791.

170. Silver J, Ogawa MY: Postnatally induced formation of the corpus callosum in acallosal mice on glia-coated cellulose bridges. Science 1983, 220:1067-1069.

17I. Kater SB, Mills LR: Regulation of growth cone behavior by calcium. J Neurosci |99|, I I:89|-899.

172. McCaig CD: Studies on the mechanism of embryonic frog nerve orientation in a small applied electric field. J Cell Sci 1989, 93:723-730

173. Ehrlicher A, Betz T, Stuhrmann B, Koch D, Milner V, Raizen MG, Kas J: Guiding neuronal growth with light. Proc Natl Acad Sci USA 2002, 99: 16024-16028.

174. Flanagan LA, Ju YE, Marg B, Osterfield M, Janmey PA: Neurite branching on deformable substrates. Neuroreport 2002 , I3:24II-24I5.

175. Bray D: Mechanical tension produced by nerve cells in tissue culture. J Cell Sci 1979, 37:391-4I0.

176. Steketee MB, Tosney KW: Three functionally distinct adhesions in filopodia: shaft adhesions control lamellar extension. Neurosci 2002, 22:807|-8083.

177. Huber AB, Kolodkin AL, Ginty DD, Cloutier JF: Signaling at the growth cone: ligand-receptor complexes and the control of axon growth and guidance. Annu Rev Neurosci 2003, 26:509-563.

178. Dickson BJ: Molecular mechanisms of axon guidance. Science 2002, 298: 1959-1964.

179. Song HJ, Poo MM: Signal transduction underlying growth cone guidance by diffusible factors. Curr Opin Neurobiol 1999, 9:355-363.

180. Wong JT, Yu WT, O'Connor TP: Transmembrane grasshopper Semaphorin I promotes axon outgrowth in vivo. Development 1997, 124:3597-3607.

18I. Ming G, Song H, Berninger B, Inagaki N, Tessier-Lavigne M, Poo M: Phospholipase $C$-gamma and phosphoinositide 3-kinase mediate cytoplasmic signaling in nerve growth cone guidance. Neuron 1999, 23:139-148.

182. Bagnard D, Lohrum M, Uziel D, Puschel AW, Bolz J: Semaphorins act as attractive and repulsive guidance signals during the development of cortical projections. Development 1998, I 25:5043-5053.

183. Colamarino SA, Tessier-Lavigne M: The axonal chemoattractant netrin- $I$ is also a chemorepellent for trochlear motor axons. Cell 1995, 81:62I-629.

184. Hanson MG, Landmesser LT: Normal patterns of spontaneous activity are required for correct motor axon guidance and the expression of specific guidance molecules. Neuron 2004, 43:687-70I

185. Gu X, Spitzer NC: Distinct aspects of neuronal differentiation encoded by frequency of spontaneous $\mathrm{Ca}^{2+}$ transients. Nature 1995, 375:784-787.

186. Jan YN, Jan LY: The peripheral nervous system. In The Development of Drosophila melanogaster Volume 2. Edited by: Bate M, MartínezArias A. Cold Spring Harbour, New York: Cold Spring Harbour Press; 1993:1207-1244.
187. Bhat KM: Cell-cell signalling during neurogenesis: some answers and many questions. Int J Dev Biol 1998, 42:127-139.

188. Prokop A: Integrating bits and pieces - synapse formation in Drosophila embryos. Cell Tissue Res 1999, 297:169-186.

189. Schmidt H, Rickert C, Bossing T, Vef O, Urban J, Technau GM: The embryonic central nervous system lineages of Drosophila melanogaster. II. Neuroblast lineages derived from the dorsal part of the neuroectoderm. Dev Biol 1997, 198:186-204.

190. Bossing T, Udolph G, Doe CQ, Technau GM: The embryonic CNS lineages of Drosophila melanogaster. I. The lineages derived from the ventral half of the truncal neuroectoderm. Dev Biol 1996, 179:4|-64

191. Landgraf M, Bossing T, Technau GM, Bate M: The origin, location, and projection of the embryonic abdominal motorneurons of Drosophila. I Neurosci 1997, 17:9642-9655.

192. Merritt DJ, Whitington PM: Central projections of sensory neurons in the Drosophila embryo correlate with sensory modality, soma position, and proneural gene function. I Neurosci 1995, 15:1755-1767.

193. Prokop A: Organisation of the efferent system and structure of neuromuscular junctions in Drosophila. In The Fly Neuromuscular Junction: Structure and Function Volume 75. 2nd edition. Edited by: Budnik V, Ruiz-Cañada C. San Diego: Elsevier Academic Press; 2006:7I-9I.

194. Ruiz-Cañada C, Budnik V: Introduction on the use of the Drosophila embryonic/larval neuromuscular junction as a model system to study synapse development and function, and a brief summary of pathfinding and target recognition. In The Fly Neuromuscular Junction: Structure and Function Volume 75. 2nd edition. Edited by: Budnik V, Ruiz-Cañada C. San Diego: Elsevier Academic Press; 2006:2-33

195. Ghysen A, Dambly-Chaudière C, Aceves E, Jan L-Y, Jan Y-N: Sensory neurons and peripheral pathways in Drosophila embryos. Roux's Arch Dev Biol 1986, 195:28I-289.

196. Hartenstein V: Development of Drosophila larval sensory organs: spatiotemporal pattern of sensory neurones, peripheral axonal pathways and sensilla differentiation. Development 1988, 102:869-886

197. Giniger E, Jan LY, Jan YN: Specifying the path of the intersegmental nerve of the Drosophila embryo: a role for Delta and Notch. Development 1993, I 17:431-440.

198. Younossi-Hartenstein A, Hartenstein V: The role of the tracheae and musculature during pathfinding of Drosophila embryonic sensory axons. Dev Biol 1993, 158:430-447.

199. Harris KL, Whitington PM: Pathfinding by sensory axons in Drosophila: substrates and choice points in early Ich5 axon outgrowth. J Neurobiol 200I, 48:243-255.

200. Grueber WB, Ye B, Yang CH, Younger S, Borden K, Jan LY, Jan YN: Projections of Drosophila multidendritic neurons in the central nervous system: links with peripheral dendrite morphology. Development 2007, 134:55-64.

20I. Landgraf M, Jeffrey V, Fujioka M, Jaynes JB, Bate M: Embryonic origins of a motor system: motor dendrites form a myotopic map in Drosophila. PLoS Biol 2003, I:22I -230.

202. Lee S, Harris K-L, Whitington PM, Kolodziej PA: short stop is allelic to kakapo, and encodes rod-like cytoskeletal-associated proteins required for axon extension. J Neurosci 2000, 20:1096-1108.

203. Parsons L, Harris KL, Turner K, Whitington PM: Roundabout gene family functions during sensory axon guidance in the Drosophila embryo are mediated by both Slit-dependent and Slit-independent mechanisms. Dev Biol 2003, 264:363-375.

204. Bates KE, Whitington PM: Semaphorin 2 a secreted by oenocytes signals through plexin B and plexin A3 to guide sensory axons in the Drosophila embryo. Dev Biol 2007, 302:522-535.

205. Rajagopalan S, Nicolas E, Vivancos V, Berger J, Dickson BJ: Crossing the midline: roles and regulation of Robo receptors. Neuron 2000, 28:767-777.

206. Lin DM, Fetter RD, Kopczynski C, Grenningloh G, Goodman CS: Genetic analysis of Fasciclin II in Drosophila: defasciculation, refasciculation, and altered fasciculation. Neuron 1994, 13:1055-1069.

207. Keleman K, Rajagopalan S, Cleppien D, Teis D, Paiha K, Huber LA, Technau GM, Dickson BJ: Comm sorts robo to control axon guidance at the Drosophila midline. Cell 2002, I 1 0:4I5-427. 
208. Bonkowsky JL, Yoshikawa S, O'Keefe DD, Scully AL, Thomas JB: Axon routing across the midline controlled by the Drosophila Derailed receptor. Nature 1999, 402:540-544.

209. Truman JW, Schuppe H, Shepherd D, Williams DW: Developmental architecture of adult-specific lineages in the ventral CNS of Drosophila. Development 2004, I 3 I:5 167-5 I84.

210. Löhr R, Godenschwege T, Buchner E, Prokop A: Compartmentalisation of central neurons in Drosophila: a new strategy of mosaic analysis reveals localisation of pre-synaptic sites to specific segments of neurites. J Neurosci 2002, 22:10357-10367.

21 I. Bossing T, Brand AH: Dephrin, a transmembrane ephrin with a unique structure, prevents interneuronal axons from exiting the Drosophila embryonic CNS. Development 2002, I 29:4205-42 I8.

212. Keleman K, Dickson BJ: Short- and long-range repulsion by the Drosophila Unc5 netrin receptor. Neuron 200I, 32:605-617.

213. Labrador JP, O'Keefe D, Yoshikawa S, McKinnon RD, Thomas JB Bashaw G]: The homeobox transcription factor Even-skipped regulates Netrin-receptor expression to control dorsa motor-axon projections in Drosophila. Curr Biol 2005, I5:1413-1419.

214. Boyle M, Nighorn A, Thomas JB: Drosophila Eph receptor guides specific axon branches of mushroom body neurons. Development 2006, I33:1845-1854.

215. Whitington $P M$, Quilkey $C$, Sink $H$ : Necessity and redundancy of guidepost cells in the embryonic Drosophila CNS. Int J Dev Neurosci 2004, 22: 157-163.

216. Wolf $\mathrm{BD}$, Chiba $\mathrm{A}$ : Axon pathfinding proceeds normally despite disrupted growth cone decisions at CNS midline. Development 2000, 1 27:2001-2009.

217. Whitington PM, Sink H: Development of a polar morphology by identified embryonic motoneurons. Int J Dev Neurosci 2004 , 22:39-45.

218. Jacobs JR, Goodman CS: Embryonic development of axon pathways in the Drosophila CNS. I. A glial scaffold appears before the first growth cones. J Neurosci 1989, 9:2402-24 I I.

219. Hidalgo $A$, Brand $\mathrm{AH}$ : Targeted neuronal ablation: the role of pioneer neurons in guidance and fasciculation in the CNS of Drosophila. Development 1997, I 24:3253-3262.

220. Lin DM, Auld V], Goodman CS: Targeted neuronal cell ablation in the Drosophila embryo: pathfinding by follower growth cones in the absence of pioneers. Neuron 1995, 14:707-7|15.

22I. Jacobs JR, Hiromi Y, Patel NH, Goodman CS: Lineage, migration, and morphogenesis of longitudinal glia in the Drosophila CNS as revealed by a molecular lineage marker. Neuron 1989 , 2:1625-|63|.

222. Hidalgo A, Urban J, Brand $\mathrm{AH}$ : Targeted ablation of glia disrupts axon tract formation in the Drosophila CNS. Development 1995, I $21: 3703-3712$

223. Hidalgo A, Booth GE: Glia dictate pioneer axon trajectories in the Drosophila embryonic CNS. Development 2000 I 27:393-402.

224. Hiramoto M, Hiromi Y, Giniger E, Hotta Y: The Drosophila Netrin receptor Frazzled guides axons by controlling Netrin distribution. Nature 2000, 406:886-889.

225. Kolodziej PA, Timpe LC, Mitchell KJ, Fried SR, Goodman CS, Yeh-Jan $\mathrm{L}$, Jan YN: frazzled encodes a Drosophila member of the DCC immunoglobulin subfamily and is required for CNS and motor axon guidance. Cell 1996, 87:197-204.

226. Iwai Y, Usui T, Hirano S, Steward R, Takeichi M, Uemura T: Axon patterning requires $\mathrm{DN}$-cadherin, a novel neuronal adhesion receptor, in the Drosophila embryonic CNS. Neuron 1997, 19:77-89.

227. de la Escalera S, Bockamp EO, Moya F, Piovant M, Jimenez F: Characterization and gene cloning of neurotactin, a Drosophila transmembrane protein related to cholinesterases. EMBO 1990, 9:3593-3601.

228. Hortsch M, Patel NH, Bieber AJ, Traquina ZR, Goodman CS: Drosophila neurotactin, a surface glycoprotein with homology to serine esterases, is dynamically expressed during embryogenesis. Development 1990, I I 0:1327-1340.

229. Zinn K, McAllister L, Goodman CS: Sequence analysis and neuronal expression of fasciclin I in grasshopper and Drosophila. Cell 1988, 53:577-587.

230. Nose A, Mahajan VB, Goodman CS: Connectin: A homophilic cell adhesion molecule expressed on a subset of muscles and the motoneurons that innervate them in Drosophila. Cell 1992, 70:553-567.

23I. Meadows LA, Gell D, Broadie K, Gould AP, White RAH: The cell adhesion molecule, Connectin, and the development of the Drosophila neuromuscular system. J Cell Science 1994, I07:321-328.

232. Snow PM, Bieber AJ, Goodman CS: Fasciclin III: a nove homophilic adhesion molecule in Drosophila. Cell 1989, 59:313-323.

233. Bieber AJ, Snow PM, Hortsch M, Patel NH, Jacobs JR, Traquina ZR, Schilling J, Goodman CS: Drosophila neuroglian: a member of the immunoglobulin superfamily with extensive homology to the vertebrate neural adhesion molecule LI. Cell 1989, 59:447-460.

234. Grenningloh G, Rehm EJ, Goodman CS: Genetic analysis of growth cone guidance in Drosophila: Fasciclin II functions as a neuronal recognition molecule. Cell 1991, 67:45-57.

235. Elkins T, Hortsch M, Bieber AJ, Snow PM, Goodman CS: Drosophila fasciclin $I$ is a novel homophilic adhesion molecule that along with fasciclin III can mediate cell sorting. J Cell Biol 1990, I 10:1825-1832.

236. Landgraf M, Sánchez-Soriano N, Technau GM, Urban J, Prokop A: Charting the Drosophila neuropile: a strategy for the standardised characterisation of genetically amenable neurites. Dev Biol 2003, 260:207-225.

237. Darboux I, Barthalay Y, Piovant M, Hipeau-Jacquotte R: The structure-function relationships in Drosophila neurotactin show that cholinesterasic domains may have adhesive properties. EMBO J 1996, I 5:4835-4843.

238. Barthalay $Y$, Hipeau-Jacquotte $R$, de la Escalera $S$, Jiménez $F$, Piovant M: Drosophila neurotactin mediates heterophilic cell adhesion. EMBO J 1990, 9:3603-3609.

239. Frémion F, Darboux I, Diano M, Hipeau-Jacquotte R, Seeger MA, Piovant $M$ : Amalgam is a ligand for the transmembrane receptor neurotactin and is required for neurotactin-mediated cell adhesion and axon fasciculation in Drosophila. EMBO J 2000, 1 9:4463-4472.

240. Dubreuil RR, MacVicar G, Dissanayake S, Liu C, Homer D, Hortsch $M$ : Neuroglian-mediated cell adhesion induces assembly of the membrane skeleton at cell contact sites. J Cell Biol 1996, 133:647-655.

24I. Speicher S, Garcia-Alonso L, Carmena A, Martín-Bermudo MD, de la Escalera $S$, Jiménez F: Neurotactin functions in concert with other identified CAMs in growth cone guidance in Drosophila. Neuron 1998, 20:221-233.

242. Liebl EC, Rowe RG, Forsthoefel DJ, Stammler AL, Schmidt ER, Turski $M$, Seeger MA: Interactions between the secreted protein Amalgam, its transmembrane receptor Neurotactin and the Abelson tyrosine kinase affect axon pathfinding. Development 2003, 130:3217-3226.

243. $\mathrm{Yu} \mathrm{H}-\mathrm{H}$, Araj $\mathrm{HH}$, Ralls SA, Kolodkin AL: The transmembrane Semaphorin Sema $I$ is required in Drosophila for embryonic motor and CNS axon guidance. Neuron 1998, 20:207-220.

244. Ayoob JC, Terman JR, Kolodkin AL: Drosophila Plexin B is a Sema-2a receptor required for axon guidance. Development 2006, 133:2125-2135.

245. Winberg ML, Noordermeer JN, Tamagnone L, Comoglio PM, Spriggs MK, Tessier-Lavigne M, Goodman CS: Plexin A is a neuronal semaphorin receptor that controls axon guidance. Cell 1998 , 95:903-916

246. Van Berkum MF, Goodman CS: Targeted disruption of $\mathrm{Ca}^{2+}$-calmodulin signaling in Drosophila growth cones leads to stalls in axon extension and errors in axon guidance. Neuron 1995, 14:43-56.

247. Dunlop J, Morin X, Corominas M, Serras F, Tear G: glaikit is essential for the formation of epithelial polarity and neuronal development. Curr Biol 2004, 14:2039-2045.

248. Fradkin LG, van Schie M, Wouda RR, de Jong A, Kamphorst JT, Radjkoemar-Bansraj M, Noordermeer JN: The Drosophila Wnt5 protein mediates selective axon fasciculation in the embryonic central nervous system. Dev Biol 2004, 272:362-375.

249. Fambrough D, Pan D, Rubin GM, Goodman CS: The cell surface metalloprotease/disintegrin Kuzbanian is required for axonal extension in Drosophila. Proc Natl Acad Sci USA 1996, 93:13233-13238. 
250. Sun Q, Bahri S, Schmid A, Chia W, Zinn K: Receptor tyrosine phosphatases regulate axon guidance across the midline of the Drosophila embryo. Development 2000, I27:80I-8I2.

25I. Giniger E, Tietje K, Jan LY, Jan YN: Iola encodes a putative transcription factor required for axon growth and guidance in Drosophila. Development 1994, I 20:1385-1398.

252. Goeke S, Greene EA, Grant PK, Gates MA, Crowner D, Aigaki T, Giniger E: Alternative splicing of lola generates 19 transcription factors controlling axon guidance in Drosophila. Nat Neurosci 2003, 6:917-924.

253. Rajagopalan S, Vivancos V, Nicolas E, Dickson BJ: Selecting a longitudinal pathway: Robo receptors specify the lateral position of axons in the Drosophila CNS. Cell 2000, I 03:1033-1045.

254. Simpson JH, Bland KS, Fetter RD, Goodman CS: Short-range and long-range guidance by Slit and its Robo receptors: A combinatorial code of Robo receptors controls lateral position. Cell 2000, 103:1019-1032.

255. Zlatic $M$, Landgraf $M$, Bate $M$ : Genetic specification of axonal arbors: atonal regulates robo3 to position terminal branches in the Drosophila nervous system. Neuron 2003, 37:4I-5I.

256. Godenschwege TA, Simpson JH, Shan X, Bashaw GJ, Goodman CS, Murphey RK: Ectopic expression in the giant fiber system of Drosophila reveals distinct roles for roundabout (Robo) Robo2, and Robo3 in dendritic guidance and synaptic connectivity. J Neurosci 2002, 22:3। I7-3। 29.

257. Crowner D, Madden K, Goeke S, Giniger E: Lola regulates midline crossing of CNS axons in Drosophila. Development 2002 I 29:1317-1325.

258. Kidd T, Bland KS, Goodman CS: Slit is the midline repellent for the Robo receptor in Drosophila. Cell 1999, 96:785-794

259. Johnson KG, Ghose A, Epstein E, Lincecum J, O'Connor MB, Van Vactor $\mathrm{D}$ : Axonal heparan sulfate proteoglycans regulate the distribution and efficiency of the repellent slit during midline axon guidance. Curr Biol 2004, 14:499-504.

260. Rhee J, Mahfooz NS, Arregui C, Lilien J, Balsamo J, VanBerkum MF: Activation of the repulsive receptor Roundabout inhibits $\mathbf{N}$ cadherin-mediated cell adhesion. Nat Cell Biol 2002, 4:798-805.

26I. Elkins T, Zinn K, McAllister L, Hoffmann FM, Goodman CS: Genetic analysis of a Drosophila neural cell adhesion molecule: Interaction of fasciclin $I$ and abelson tyrosine kinase mutations. Cell 1990, 60:565-575

262. Callahan CA, Muralidhar MG, Lundgren SE, Scully AL, Thomas JB: Control of neuronal pathway selection by a Drosophila receptor protein-tyrosine kinase family member. Nature 1995 376: $171-174$.

263. Yoshikawa S, McKinnon RD, Kokel M, Thomas JB: Wnt-mediated axon guidance via the Drosophila Derailed receptor. Nature 2003, 422:583-588.

264. Patel NH, Schafer B, Goodman CS, Holmgren R: The role of segment polarity genes during Drosophila neurogenesis. Genes Dev 1989, 3:890-904.

265. Mitchell KJ, Doyle JL, Serafini T, Kennedy TE, Tessier-Lavigne M, Goodman CS, Dickson BJ: Genetic analysis of Netrin genes in Drosophila: Netrins guide CNS commissural axons and peripheral motor axons. Neuron 1996, I 7:203-215.

266. Harris R, Sabatelli LM, Seeger MA: Guidance cues at the Drosophila CNS midline: identification and characterisation of two Drosophila Netrin/UNC-6 homologs. Neuron 1996, I 7:217-228.

267. Brankatschk M, Dickson BJ: Netrins guide Drosophila commissural axons at short range. Nat Neurosci 2006, 9:188-194.

268. Kennedy TE, Wang H, Marshall W, Tessier-Lavigne M: Axon guidance by diffusible chemoattractants: A gradient of netrin protein in the developing spinal cord. I Neurosci 2006, 26:8866-8874

269. Joly W, Mugat B, Maschat F: Engrailed controls the organisation of the ventral nerve cord through frazzled regulation. Dev Biol 2007, 30I:542-554.

270. Rothberg JM, Hartley DA, Walther Z, Artavanis-Tsakonas S: slit: an EGF-homologous locus of $D$. melanogaster involved in the development of the embryonic central nervous system. Cell 1988, 55:1047-1059.

27I. Simpson JH, Kidd T, Bland KS, Goodman CS: Short-range and long-range guidance by slit and its Robo receptors. Robo and Robo2 play distinct roles in midline guidance. Neuron 2000 28:753-766.
272. Schimmelpfeng K, Gögel S, Klämbt C: The function of leak and kuzbanian during growth cone and cell migration. Mech Dev 200I, 106:25-36.

273. Bhat KM: Slit-roundabout signaling neutralizes netrin-Frazzled-mediated attractant cue to specify the lateral positioning of longitudinal axon pathways. Genetics 2005, I 70:|49-I59.

274. Emerson MM, Van Vactor D: Robo is Abl to block N-Cadherin function. Nat Cell Biol 2002, 4:E227-230.

275. Ratnaparkhi A, Banerjee S, Hasan G: Altered levels of $\mathbf{G q}$ activity modulate axonal pathfinding in Drosophila. J Neurosci 2002, 22:4499-4508.

276. Stein $E$, Tessier-Lavigne M: Hierarchical organization of guidance receptors: silencing of netrin attraction by slit through a Robo/DCC receptor complex. Science 200I, 29 I: 1928-1938.

277. Kidd T, Russell C, Goodman CS, Tear G: Dosage-sensitive complementary functions of roundabout and commissureless control axon crossing of the CNS midline. Neuron 1998 , 20:25-33.

278. Georgiou M, Tear G: Commissureless is required both in commissural neurones and midline cells for axon guidance across the midline. Development 2002, I 29:2947-2956.

279. Myat A, Henry P, McCabe V, Flintoft L, Rotin D, Tear G: Drosophila Nedd4, a ubiquitin ligase, is recruited by Commissureless to control cell surface levels of the roundabout receptor. Neuron 2002, 35:447-459.

280. Keleman K, Ribeiro C, Dickson BJ: Comm function in commissural axon guidance: cell-autonomous sorting of Robo in vivo. Nat Neurosci 2005, 8: I56-I63.

28I. Sabatier C, Plump AS, Le M, Brose K, Tamada A, Murakami F, Lee EY, Tessier-Lavigne $M$ : The divergent Robo family protein rig-I/ Robo3 is a negative regulator of slit responsiveness required for midline crossing by commissural axons. Cell 2004, I | 7:157-169.

282. Garbe DS, Das A, Dubreuil RR, Bashaw Gl: \{beta\}-Spectrin functions independently of Ankyrin to regulate the establishment and maintenance of axon connections in the Drosophila embryonic CNS. Development 2007, I 34:273-284.

283. Hülsmeier J, Pielage J, Rickert C, Technau GM, Klämbt C, Stork T: Distinct functions of alpha\}-Spectrin and \{beta\}-Spectrin during axonal pathfinding. Development 2007, I 34:7| 3-722

284. Fan X, Labrador JP, Hing $H$, Bashaw GJ: Slit stimulation recruits Dock and Pak to the roundabout receptor and increases Rac activity to regulate axon repulsion at the CNS midline. Neuron 2003, 40: II3-I27.

285. Yu TW, Hao JC, Lim W, Tessier-Lavigne M, Bargmann Cl: Shared receptors in axon guidance: SAX-3/Robo signals via UNC-34/ Enabled and a Netrin-independent UNC-40/DCC function. Nat Neurosci 2002, 5:1147-1 I54.

286. Bashaw GJ, Kidd T, Murray D, Pawson T, Goodman CS: Repulsive axon guidance: Abelson and Enabled play opposing roles downstream of the roundabout receptor. Cell 2000 | 0 |:703-7| 5

287. Hsouna A, Kim YS, VanBerkum MF: Abelson tyrosine kinase is required to transduce midline repulsive cues. J Neurobiol 2003, 57: I5-30.

288. Forsthoefel DJ, Liebl EC, Kolodziej PA, Seeger MA: The Abelson tyrosine kinase, the Trio GEF and Enabled interact with the Netrin receptor Frazzled in Drosophila. Development 2005, 132:1983-1994.

289. Fritz JL, VanBerkum MF: Calmodulin and son of sevenless dependent signaling pathways regulate midline crossing of axons in the Drosophila CNS. Development 2000, 127:199|-2000.

290. Yang L, Bashaw GJ: Son of sevenless directly links the Robo receptor to rac activation to control axon repulsion at the midline. Neuron 2006, 52:595-607.

29I. Lee S, Nahm M, Lee M, Kwon M, Kim E, Zadeh AD, Cao H, Kim HJ, Lee $\mathrm{ZH}$, Oh SB, et al: The F-actin-microtubule crosslinker Shot is a platform for Krasavietz-mediated translational regulation of midline axon repulsion. Development 2007 | 34: | 767- I 777

292. Steigemann P, Molitor A, Fellert S, Jäckle H, Vorbrüggen G: Heparan sulfate proteoglycan syndecan promotes axonal and myotube guidance by slit/robo signaling. Curr Biol 2004, I 4:225-230.

293. Fox AN, Zinn K: The heparan sulfate proteoglycan syndecan is an in vivo ligand for the Drosophila LAR receptor tyrosine phosphatase. Curr Biol 2005, I 5:|70I-I7II. 
294. Desai C], Sun Q, Zinn K: Tyrosine phosphorylation and axon guidance: of mice and flies. Curr Opin Neurobiol 1997, 7:70-74.

295. Onel S, Bolke L, Klämbt C: The Drosophila ARF6-GEF Schizo controls commissure formation by regulating Slit. Development 2004, I 3 I:2587-2594.

296. Stevens A, Jacobs JR: Integrins regulate responsiveness to Slit repellent signals. J Neurosci 2002, 22:4448-4455

297. Kaprielian Z, Runko E, Imondi R: Axon guidance at the midline choice point. Dev Dyn 200I, 22 I:I54-I8I.

298. Garbe DS, Bashaw GJ: Axon guidance at the midline: from mutants to mechanisms. Crit Rev Biochem Mol Biol 2004 39:3|9-34I.

299. Jen JC, Chan WM, Bosley TM, Wan J, Carr JR, Rub U, Shattuck D, Salamon G, Kudo LC, Ou J, et al.: Mutations in a human ROBO gene disrupt hindbrain axon pathway crossing and morphogenesis. Science 2004, 304:1509-1513.

300. Schrader S, Merritt DJ: Central projections of Drosophila sensory neurons in the transition from embryo to larva. J Comp Neurol 2000, 425:34-44.

30I. Bate M, Broadie K: Wiring by fly: The neuromuscular system of the Drosophila embryo. Neuron 1995, 15:513-525.

302. Choksi SP, Southall TD, Bossing T, Edoff K, de Wit E, Fischer BE, van Steensel B, Micklem G, Brand AH: Prospero acts as a binary switch between self-renewal and differentiation in Drosophila neural stem cells. Dev Cell 2006, I I:775-789.

303. Kuzin A, Brody T, Moore AW, Odenwald WF: Nerfin-I is required for early axon guidance decisions in the developing Drosophila CNS. Dev Biol 2005, 277:347-365.

304. Butler SJ, Tear G: Getting axons onto the right path: the role of transcription factors in axon guidance. Development 2007. 134:439-448.

305. Tolhuis B, de Wit E, Muijrers I, Teunissen H, Talhout W, van Steensel $B$, van Lohuizen M: Genome-wide profiling of PRCI and PRC2 Polycomb chromatin binding in Drosophila melanogaster. Nat Genet 2006, 38:694-699.

306. Pollock JA, Benzer S: Transcript localization of four opsin genes in the three visual organs of Drosophila; $\mathrm{RH} 2$ is ocellus specific. Nature 1988, 333:779-782.

307. Steller H, Fischbach KF, Rubin GM: Disconnected: a locus required for neuronal pathway formation in the visual system of Drosophila. Cell 1987, 50: II39-II53.

308. Boschert U, Ramos RG, Tix S, Technau GM, Fischbach KF: Genetic and developmental analysis of irreC, a genetic function required for optic chiasm formation in Drosophila. I Neurogenet 1990, 6:|53-|7|.

309. Tix S, Minden JS, Technau GM: Pre-existing neuronal pathways in the developing optic lobes of Drosophila. Development 1989 1 05:739-746.

310. Tix S, Bate M, Technau GM: Pre-existing neuronal pathways in the leg imaginal discs of Drosophila. Development 1989 , 107:855-862.

3II. Palka J: Neuronal specificity and its development in the Drosophila wing disc and its derivatives. I Neurobiol 1993, 24:788-802.

312. Murray MA, Schubiger M, Palka J: Neuron differentiation and axon growth in the developing wing of Drosophila melanogaster. Dev Biol 1984, 104:259-273.

313. Canal I, Acebes A, Ferrús A: Single neuron mosaics of the Drosophila gigas mutant project beyond normal targets and modify behaviour. J Neurosci 1998, I 8:999-1008.

3|4. Chen BE, Kondo M, Garnier A, Watson FL, Puettmann-Holgado R, Lamar DR, Schmucker D: The molecular diversity of Dscam is functionally required for neuronal wiring specificity in Drosophila. Cell 2006, 125:607-620.

315. Phillis R, Statton D, Caruccio P, Murphey RK: Mutations in the 8 $\mathrm{kDa}$ dynein light chain gene disrupt sensory axon projections in the Drosophila imaginal CNS. Development 1996 I 22:2955-2963.

316. Prokop A, Meinertzhagen IA: Development and structure of synaptic contacts in Drosophila. Semin Cell Dev Biol 2006, 17:20-30.

317. Fischbach K-F, Dittrich APM: The optic lobe of Drosophila melanogaster. I. A Golgi analysis of wild-type structure. Cell Tissue Res 1989, 258:44|-475.

318. Mast JD, Prakash S, Chen PL, Clandinin TR: The mechanisms and molecules that connect photoreceptor axons to their targets in Drosophila. Semin Cell Dev Biol 2006, I7:42-49.
319. Otsuna $\mathrm{H}$, Ito $\mathrm{K}$ : Systematic analysis of the visual projection neurons of Drosophila melanogaster. I. Lobula-specific pathways. J Comp Neurol 2006, 497:928-958.

320. Morales J, Hiesinger PR, Schroeder AJ, Kume K, Verstreken P, Jackson FR, Nelson DL, Hassan BA: Drosophila fragile X protein, DFXR, regulates neuronal morphology and function in the brain. Neuron 2002, 34:961-972.

321. Srahna M, Leyssen M, Choi CM, Fradkin LG, Noordermeer JN, Hassan BA: A signaling network for patterning of neuronal connectivity in the Drosophila brain. PLoS Biol 2006, 4:e348.

322. Hassan BA, Bermingham NA, He Y, Sun Y, Jan YN, Zoghbi HY, Bellen $\mathrm{HJ}$ : atonal regulates neurite arborization but does not act as a proneural gene in the Drosophila brain. Neuron 2000, 25:549-561.

323. Heisenberg M: Mushroom body memoir: from maps to models. Nat Rev Neurosci 2003, 4:266-275.

324. Davis RL: Olfactory memory formation in Drosophila: from molecular to systems neuroscience. Annu Rev Neurosci 2005, 28:275-302.

325. Jefferis GS, Marin EC, Watts RJ, Luo L: Development of neuronal connectivity in Drosophila antennal lobes and mushroom bodies. Curr Opin Neurobiol 2002, I 2:80-86.

326. Allen MJ, Godenschwege TA, Tanouye MA, Phelan P: Making an escape: development and function of the Drosophila giant fibre system. Semin Cell Dev Biol 2006, 17:3I-4I.

327. Kamikouchi A, Shimada T, Ito K: Comprehensive classification of the auditory sensory projections in the brain of the fruit fly Drosophila melanogaster. J Comp Neurol 2006, 499:3 I7-356.

328. Nübler-Jung K, Arendt $D$ : Is ventral in insects dorsal in vertebrates? A history of embryological arguments favouring axis inversion in chordate ancestors. Roux's Arch Dev Biol 1994, 203:357-366.

329. Nassif C, Noveen A, Hartenstein V: Early development of the Drosophila brain: III. The pattern of neuropile founder tracts during the larval period. J Comp Neurol 2003, 455:417-434.

330. Jankovics $F$, Brunner $D$ : Transiently reorganized microtubules are essential for zippering during dorsal closure in Drosophila melanogaster. Dev Cell 2006, I I:375-385.

33I. Tear G, Harris R, Sutaria S, Kilomanski K, Goodman CS, Seeger MA commissureless controls growth cone guidance across the CNS midline in Drosophila and encodes a novel membrane protein. Neuron 1996, 16:50|-5|4.

332. Fradkin LG, Noordermeer JN, Nusse R: The Drosophila Wnt protein DWnt-3 is a secreted glycoprotein localized on the axon tracts of the embryonic CNS. Dev Biol 1995, 168:202-213.

333. Hopmann R, Miller KG: A balance of capping protein and profilin functions is required to regulate actin polymerization in Drosophila bristle. Mol Biol Cell 2003, I 4: I 18-128.

334. Rogers SL, Wiedemann U, Stuurman N, Vale RD: Molecular requirements for actin-based lamella formation in Drosophila S2 cells. J Cell Biol 2003, I62:1079-1088.

335. Zhang YQ, Bailey AM, Matthies HJ, Renden RB, Smith MA, Speese SD, Rubin GM, Broadie K: Drosophila fragile $\mathbf{X}$-related gene regulates the MAPIB homolog Futsch to control synaptic structure and function. Cell 200I, 107:59I-603.

Publish with Biomed Central and every scientist can read your work free of charge

"BioMed Central will be the most significant development for disseminating the results of biomedical research in our lifetime. "

Sir Paul Nurse, Cancer Research UK

Your research papers will be:

- available free of charge to the entire biomedical community

- peer reviewed and published immediately upon acceptance

- cited in PubMed and archived on PubMed Central

- yours - you keep the copyright 